University of Zurich

Department of Economics

Working Paper Series

ISSN 1664-7041 (print)

ISSN 1664-705X (online)

Working Paper No. 210

\title{
Frequent job changes can signal poor work attitude and reduce employability
}

Alain Cohn, Michel André Maréchal, Frédéric Schneider and Roberto A. Weber

Revised version, November 2019 


\title{
Frequent job changes can signal poor work attitude and reduce employability
}

\author{
Alain Cohn* Michel André Maréchal ${ }^{\dagger} \quad$ Frédéric Schneider ${ }^{\ddagger}$ \\ Roberto A. Weber ${ }^{\dagger}$
}

November 14, 2019

\begin{abstract}
We study whether employment history provides information about a worker's "work attitude," i.e., the tendency to act cooperatively and reliably in the workplace. We conjecture that, holding all else equal, frequent job changes can indicate poor work attitude and that this information is transmitted through employment histories. We find support for this hypothesis across three studies that employ complementary lab, field, and survey experiments, as well as in labor market panel data. First, a tightly controlled laboratory labor market experiment demonstrates that prior employment information allows employers to screen for reliable and cooperative workers and that these workers obtain better employment outcomes. Second, we conduct a field experiment that varies the frequency of job changes in applicants' resumes and find that those with fewer job changes receive substantially more callbacks from prospective employers. Third, a survey experiment with Human Resources professionals confirms that the resume manipulations in the field study create different perceptions of work attitude and that these largely account for the callback differences. Finally, we find evidence consistent with our hypothesized relationships in empirical labor market data. Our work highlights the potential importance of job history as a signal of work attitude in labor markets, and points to a potential cost of frequent job changes.
\end{abstract}

${ }^{*}$ University of Michigan, School of Information, 105 S State St, Ann Arbor, Michigan 48109, United States

$\dagger^{\dagger}$ Department of Economics, University of Zürich, Blümlisalpstrasse 10, 8006 Zürich, Switzerland.

$\ddagger$ Judge Business School, University of Cambridge, Trumpington Street, Cambridge CB2 1AG, United Kingdom.

We greatly appreciate research assistance provided by Sara Antunes, Nadja Jehli, Pascal Rast, Lukas Schürch and Lexi Schubert. We thank Björn Bartling, Mitchell Hoffman, Eva Ranehill, Florian Zimmermann and participants at several seminars and conferences for valuable comments and suggestions. We are also grateful to several anonymous referees and to the editor, Giovanni Peri, for guidance in improving this paper. 


\section{Introduction}

Traditional accounts of human capital mainly emphasize the role of cognitive or physical skills and job experience in labor market success (e.g., Becker 1964). More recent research highlights the importance of non-cognitive or social and behavioral skills (Bowles, Gintis, and Osborne 2001; Heckman, Stixrud, and Urzua 2006) and argues that the labor market increasingly rewards such traits (Deming 2017). These characteristics include, for example, a worker's reliability, trustworthiness, self-control, loyalty and ability to work well with others (e.g., Heckman and Rubinstein 2001; Dohmen et al. 2009; Lindqvist and Vestman 2011). For simplicity, we refer to this broad set of individual characteristicswhich include many traits unrelated to traditional notions of skill or expertise - as "work attitude." A central idea of this literature is that workers who exhibit a positive work attitude are more desirable to employers and obtain better labor market outcomes. Indeed, many employers rate workers' "attitude" as an important determinant of hiring decisions and note "poor attitude, motivation or personality" as a reason why they forgo hiring applicants for open positions (Green, Machin, and Wilkinson 1998; Bowles, Gintis, and Osborne 2001). For example, in describing his company's hiring philosophy, Herb Kelleher, founder and former CEO of Southwest Airlines, stated that, "We look for attitudes. We'll train you on whatever you need to do, but the one thing we can't do is change inherent attitudes in people" (Lee 1994). ${ }^{1}$

An important open question is how information about work attitude is conveyed in labor markets. One piece of observable and typically verifiable information in most job applications is employment history — what positions an applicant has previously held, at which firms, and for how long. While an applicant's work history may provide many signals related to a worker's characteristics, we propose that employers may often view frequent job changes as reflective of a worker's poor attitude. As a result, employers will

\footnotetext{
${ }^{1}$ In fact, this statement reflects a broader commitment by Southwest Airlines toward screening as a mechanism for sustaining a cooperative culture in an industry where team production and high degrees of complementarity between workers' tasks make work attitude important for firm success (Gittell 2005).
} 
often, ceteris paribus, find workers who change jobs frequently less desirable, particularly in contexts where work attitude is important. ${ }^{2}$ Our conjecture thus ascribes a potentially powerful role to employment history - a widely available type of information in labor markets - in providing a signal of desirable labor market qualities.

Why should applicants' job histories convey information about their work attitude? Most employment relationships require a worker to follow directions from supervisors, get along well with others and exhibit reliability and self-control. Hence, employees who do these things are often more valuable to employers and less likely to quit jobs due to personal conflicts. On the other hand, workers with poor work attitude are more likely to experience workplace conflicts and either leave or be terminated. Of course, we do not argue that work history only conveys information about work attitude, or that it is the only way employers can learn about this quality. ${ }^{3}$ Rather, our study is motivated by the possibility that the frequency of job changes, a very salient aspect of a worker's resume, may send signals regarding the extent to which that worker exhibits desirable individual characteristics that the employer may otherwise not easily detect. ${ }^{4}$

We investigate the causal relationship between work attitude, job changes, and employability using complementary laboratory, field, and survey experiments, as well as an analysis of labor market panel data. It is important to note that we do not claim to provide a comprehensive interpretation of tenure-employment relationships, but rather propose one particular mechanism through which employment history can impact subse-

\footnotetext{
${ }^{2}$ The popular business press often recognizes that frequent job changes can be associated with perceptions of "disloyalty, fickleness, and unreliability" (Trikha 2012; Suster 2010). Others have noted that workers are heterogeneous in their propensity to remain with specific employers, and that this corresponds to stable individual characteristics (Ghiselli 1974; Blumen, Kogan, and McCarthy 1955).

${ }^{3}$ Publicly observable histories form the basis of an extensive literature on screening and signaling in labor markets (Spence 1973; Arrow 1973; Stiglitz 1975; Waldman 1984). This literature has typically focused on educational attainment as a signal of human capital -i.e., skill and experience - that may facilitate learning and performing work-related tasks (Tyler, Murnane, and Willett 2000; Bedard 2001). Employers can also obtain information about prospective workers' abilities, including their work attitude, through other aspects of a worker's employment history than job changes, as well as through alternative means such as referrals by existing employees (Rees 1966; Pallais 2014; Burks et al. 2015) and social networks (Granovetter 1974; Gërxhani, Brandts, and Schram 2013).

${ }^{4}$ As a simple analogy to illustrate this point, someone who has been married and divorced multiple times may be immediately perceived as unlikely to be a reliable and cooperative marriage partner.
} 
quent labor market outcomes. ${ }^{5}$ Specifically, we test two hypotheses regarding the role of employment history as a signal of work attitude. Our first hypothesis is that frequent job changes can provide a signal of poor attitude. In other words, changing jobs frequently may be negatively associated - or perceived to be associated — with desirable attributes like reliability, self-control and ability to work well with others. Our second hypothesis is that, as a consequence of the perceived relationship between job changes and work attitude, employers will often prefer workers with fewer employment changes. We find support for both hypotheses, across several contexts. While evidence from the field provides the most compelling support for the economic significance of our findings, the lab and survey experiments deliver the clearest insights into the precise mechanism driving the relationship between job changes and employment outcomes.

The lab experiment allows us to isolate work attitude from other possible channels through which a relationship between past and future employment might occur. For example, it eliminates heterogeneity in workers' task-related skill, effort cost and experience as confounding factors. In our laboratory setting, "firms" value "workers" solely to the extent that they reliably comply with requests for high effort. Since workers with a greater tendency to provide voluntary effort are more valuable, firms can benefit from using informative signals regarding work attitude, and should thus favor contracting with more reliable and cooperative workers.

Our laboratory results show that, first, subjects in the role of workers who switch employers less frequently tend to be those who are more reliable and cooperative. Second, following an exogenous unemployment shock that requires all workers to find a new employer, job histories facilitate the signaling of these positive traits - workers with fewer job changes receive more job offers than those who have switched jobs more often. Finally,

\footnotetext{
${ }^{5}$ There may be several reasons for either positive or negative relationships between job mobility and employability. For example, workers who switch employers more often may accumulate a larger stock of general human capital - that is, skills and knowledge that are useful across jobs, firms, and industries (Mincer 1958; Becker 1962). Moreover, the reasons behind job changes are undoubtedly important for subsequent labor market outcomes (Jovanovic 1979; Topel and Ward 1992), and job mobility may have differential impacts at different points in a worker's career (Bartel 1980; Mincer and Jovanovic 1982; Farber 1999).
} 
by turning off the ability of laboratory firms to observe work histories, we show that this information is crucial in their attempts to identify reliable workers. Hence, the results demonstrate that frequent job changes can serve as a signal of poor attitude and influence employability.

We then test whether the phenomenon we identify in the laboratory is also relevant for real labor markets. To study whether frequent job changes make prospective employees less desirable to firms, we conducted a field experiment in Switzerland in which we sent resumes to several open positions for administrative and clerical jobs and then measured whether the applicants received invitations to job interviews. The resumes, for fictitious young applicants, varied the candidates' job history by random assignment. ${ }^{6}$ For every open position, we sent two applications: one with four shorter periods of tenure at different firms and one with a single period of tenure with the same total length. We counterbalanced other aspects of the resumes. In two waves of data collection, we observe significantly higher callback rates for the applicants with fewer job changes. That is, workers who change jobs more frequently are less desirable in the field study, just as they are in our laboratory study. Moreover, the size of the effect we observe in the field experiment is substantial - the difference in callback rates for applicants with one versus four prior employers is similar in magnitude to the differences in prior studies between applicants with one versus eight months of unemployment (Kroft, Lange, and Notowidigdo 2013) and white versus black candidates (Bertrand and Mullainathan 2004). To address natural concerns regarding whether our findings - involving specific kinds of applicants and jobs - generalize to other contexts, we show that our treatment effects are robust to several potential sources of heterogeneity (such as macroeconomic conditions, industry and job characteristics).

As a third step, we complement the field experiment with a survey study to obtain

\footnotetext{
${ }^{6}$ Many studies have used this method to test for other aspects of labor market discrimination, such as race, gender and unemployment duration (Riach and Rich 2002; Bertrand and Mullainathan 2004; Carlsson and Rooth 2007; Oberholzer-Gee 2008; Kroft, Lange, and Notowidigdo 2013; Eriksson and Rooth 2014; Deming et al. 2016; Bartoš et al. 2016).
} 
more information on what inferences prospective employers make when receiving the resumes in the field study. Specifically, we approached professionals with experience in human resources (HR) management to survey their impressions of the resumes used in the field study. We find that HR professionals attribute poorer work attitude to a resume with more frequent job changes - specifically, worse evaluations for the characteristics, "reliable," "team oriented," and "perseverant." Moreover, these perceived differences in work attitude, as opposed to task-related skills and experience, largely explain the HR professionals' greater stated willingness to invite applicants with fewer job changes for an interview. Thus, the survey experiment provides evidence confirming that the resumes in the field study create different perceptions of candidates' work attitude and that these perceptions are likely important drivers of callbacks.

Finally, we analyze data from the US National Longitudinal Survey of Youth 1997 (NLSY97) for relationships between individual characteristics related to work attitude, the numbers of jobs individuals have held in their careers and their labor market outcomes. This step is valuable for showing that what we find generalizes beyond the lab and the field experiment in Switzerland, although it comes at the cost of reducing how much control we have over the data and the measures of workers' characteristics and labor market outcomes. Nevertheless, we find that individuals who exhibit traits likely to be associated with poor work attitude - such as rule breaking and prior arrests - switch jobs more frequently. Moreover, more frequent prior job changes are also more likely to be associated with being unemployed. These patterns are consistent with our main hypotheses that frequent job changes can signal poor work attitude and that employers rely on this signal. We also document that these patterns are robust to different categorizations of workers and types of jobs.

Our evidence that employers discriminate against frequent job changes may have implications that go beyond the value of work history as a signal of work attitude. For instance, workers may be unwilling to undertake job changes out of fear of the negative impact on future prospective employers' perception of their attributes. This inertia or friction in 
job mobility may create inefficient matching between employees and employers. Labor market frictions are a key feature of modern search theories in macroeconomics because they provide possible explanations for the existence of unemployment and wage inequality (e.g., Petrongolo and Pissarides 2001; Rogerson, Shimer, and Wright 2005). Previous work has focused primarily on structural factors for why workers may refuse job offers and wait for more attractive ones, such as how quickly they can sell their houses (Head and Lloyd-Ellis 2012). Our paper adds to this literature by proposing a mechanism for labor market frictions that arises endogenously, through employers' preference for workers with better work attitude and limited information regarding this characteristic.

Our study is also related to a large empirical literature studying the relationship between job mobility and wage growth. While some of these studies find that mobility and wage growth are positively related (Topel and Ward 1992; Becker and Hills 1983; Bartel 1980), others find a negative relationship (Light and McGarry 1998; Mincer and Jovanovic 1982; Borjas 1981). Our paper contributes to this literature by examining the impact of variations in job mobility that have limited relationships with task-related skills or ability. We provide one possible mechanism - the signaling of work attitude - through which prior mobility may affect future outcomes, though our focus is on employability rather than wages. ${ }^{7}$

The remainder of this paper is structured as follows. The next section presents the design and results of the laboratory experiment. Section 3 reports the field experiment and the related survey experiment with HR professionals. Section 4 reports our analysis of US labor market panel data. Finally, Section 5 provides a discussion of the combined results and concludes.

\footnotetext{
${ }^{7} \mathrm{~A}$ separate strand of literature explores how job tenure with a particular firm relates to wage profiles (Dustmann and Meghir 2005; Altonji, Smith, and Vidangos 2013; Bagger et al. 2014). This is distinct from our study because we focus on job tenure solely for its signaling purposes when changing jobs between firms.
} 


\section{Laboratory Experiment}

Our laboratory experiment studies a setting in which firms value workers to the extent they exhibit positive work attitude (i.e., reliability and cooperativeness) and where task-related skills and experience are fixed across workers. Specifically, we employ a widely used experimental labor market paradigm in which incomplete contracts create incentives for inefficient shirking, meaning that workers are valuable to firms if they voluntarily provide high effort. Our experiment builds upon Brown, Falk, and Fehr (2004), closely following standard design features in the literature except where necessary for our purposes. As with all laboratory experiments, we abstract from important features of real-world labor markets in order to control factors that complicate analysis outside the laboratory. Of course, this naturally raises concerns about generalizability, which is why we also employ complementary methods to study non-laboratory labor markets.

\subsection{Experimental Design}

Each experimental labor market consists of 17 participants, of which seven are randomly assigned the role of a firm; the remaining ten participants are assigned the role of a worker. We will henceforth refer to such subjects, respectively, as "firms" and "workers." Each participant is identifiable through a permanent ID number. The experiment lasts 30 periods. In any given period, each firm can hire at most one worker, and each worker can work for at most one firm. Because labor supply exceeds labor demand, some workers are unemployed in a given period.

Every period has two stages: a hiring stage and a work stage. In the hiring stage, firms can post two types of wage offers: i) public wage offers, which any worker can accept, and ii) private wage offers, which target specific workers. Each offer contains a binding wage, $w \in\{1,2, \ldots, 100\}$, and a desired effort level, $\hat{e} \in\{1,2, \ldots, 10\}$. Firms can post as many offers as they like. All workers observe the wage and desired effort for all public offers, but private offers are only observable by the specific targeted worker. 
A private offer is thus a clear costly indication that a firm prefers a particular worker. Workers can calculate their earnings under any offer, either based on compliance with the requested effort or under any other choice of effort, and accept any offer they observe. Once a worker accepts an offer, the worker and the offering firm exit the market for that period. At the end of the hiring stage, up to seven firms and workers are matched in an employment relationship for that period.

In the second stage - the work stage - those workers who are employed choose "effort" by selecting a number, $e \in\{1,2, \ldots, 10\}$, which implies monetary costs according to an effort cost schedule, $c(e)$ (see Table 1). ${ }^{8}$ A worker's payoff from employment is equal to the wage minus the effort cost: $\pi_{\text {worker }}=w-c(e)$. Because workers simply choose a number, we eliminate any task-specific skill and experience differences between workers. Nevertheless, the employer cares about the worker's effort choice: the firm earns 10 ECU per unit of worker effort $e$, but also has to pay the wage, $w: \pi_{\text {firm }}=10 e-w \cdot{ }^{9}$ At the end of every period, firms are informed of the effort choice of any worker they employed, and all subjects are shown their earnings.

Table 1: Workers' effort cost

\begin{tabular}{lllllllllll}
\hline$e$ & 1 & 2 & 3 & 4 & 5 & 6 & 7 & 8 & 9 & 10 \\
\hline$c(e)$ & 0 & 1 & 2 & 4 & 6 & 8 & 10 & 12 & 15 & 18 \\
\hline
\end{tabular}

While aggregate payoffs are maximized if workers provide maximum effort, the unique subgame-perfect equilibrium for workers in a finitely repeated game is to shirk and provide minimal effort. Effort in this context is thus a one-dimensional proxy for the voluntary provision of costly, but productive effort at work - i.e., a measure of an employee's cooperativeness, reliability, and diligence. ${ }^{10}$

\footnotetext{
${ }^{8}$ The cost schedule is identical to that employed in Brown, Falk, and Fehr (2004) and in earlier research. This "chosen effort" approach is standard in experimental labor markets. Brüggen and Strobel (2007) show that such numerical effort choices produce similar behavior as real effort decisions.

${ }^{9}$ Unemployed workers receive $\pi_{\text {unempl }}=5$; firms without a worker receive a payoff of zero in that period. All payoffs are in "Experimental Currency Units" (ECU), converted into Swiss Francs at a rate of $20 \mathrm{ECU}=1 \mathrm{CHF}(\approx 1 \mathrm{USD})$.

${ }^{10}$ Numerous studies document positive associations between cooperative behavior in economic games, such as reciprocal behavior in the trust game or cooperation in the prisoner's dilemma, and desirable
} 
To study the role of work history as a signal of work attitude, we vary experimentally whether workers' employment histories are available to firms. In the "History" condition, each firm sees a table on the computer screen listing all ten workers in the labor market, sorted by their ID number. The table indicates, for all previous periods, either the ID of the firm that hired the worker in that period or whether that worker was unemployed. ${ }^{11}$ This provides prospective employers with a simple version of the employment histories typically contained in job applications, including job changes and spells of unemployment. By contrast, the work history table is absent in the "No History" condition. ${ }^{12}$

Our two hypotheses are that work histories provide a signal of work attitude and that firms use this signal when deciding which workers to employ. We expect that workers who provide higher voluntary effort will tend to be those who remain longer with the same employer. In addition, when employment histories are available, we expect that firms will use this information to make targeted offers to workers with fewer prior job changes.

To investigate whether firms use employment histories to screen for high-effort workers, we implement an exogenous layoff shock that forces all firms to seek a new worker. From period 17 onwards, we remove both the option for firms to make private offers to the worker they had hired in period 16 and the option for workers to see or accept public offers from the firm they had worked for in period 16. This change is permanent, meaning that no market participant is allowed to interact with their partner from period 16 in any remaining period. ${ }^{13}$ This design feature allows us to investigate which workers firms find

personality traits (Lee and Ashton 2004; McCrae and Costa 1987; Becker et al. 2012; Kagel and McGee 2014; Thielmann and Hilbig 2015; Ackermann, Fleiß, and Murphy 2016; Rustichini et al. 2016; Zhao, Ferguson, and Smillie 2016). Using representative samples, positive reciprocal behavior in economic experiments has also been linked to expressions of social or non-cognitive skills, such as being less likely to be unemployed or divorced (Fehr et al. 2002; Bellemare and Kröger 2007).

${ }^{11}$ If the worker was unemployed in a particular period, the cell is filled with a dash. Importantly, the table does not show workers' effort or wages, only the firms for which they worked (see Online Appendix 1.2). Workers saw a similar table that listed the firms by their ID number and which workers worked for a particular firm across periods.

${ }^{12}$ Note, however, that in both conditions firms have private information about the workers they previously employed.

${ }^{13}$ Participants did not know that this shock would happen in period 17 . They were informed that this restriction would come into effect at some point "between period 10 and period 20." We did this to 
desirable in a context where all workers are simultaneously — and for exogenous reasonssearching for new employment.

We conducted the study between December 2012 and May 2013, and additional sessions in June 2015, at the Laboratory for Behavioral and Experimental Economics at the University of Zurich. Each session was randomly assigned to one of the two treatments. All interactions between participants took place via the z-Tree computer interface (Fischbacher 2007). Participants received detailed written instructions and then completed a comprehension check to make sure that they understood the rules of the experiment (see Online Appendix 1.2). We read instructions aloud to establish common information. We recruited a total of 561 participants using the software h-root (Bock, Baetge, and Nicklisch 2014). Of these, 272 (16 markets) were in the No History and 289 (17 markets) in the History condition. ${ }^{14}$ Sessions lasted slightly under two hours, and participants earned an average of 51 Swiss Francs (about 54 US dollars).

\subsection{Results}

\section{Are work histories an informative signal of voluntary effort provision?}

Figure 1 shows the relationship between workers' effort and their employment history during the first 16 periods of the experiment. In the History condition, workers who had a single employer throughout periods 1 to 16 provided an average effort of 9.2, which is close to the maximum of 10 . Average effort decreases with the number of pre-shock employers to a level of 4.7 for workers with six different pre-shock employers $(p=0.040$; Mann-Whitney-U test, henceforth denoted as MWU). ${ }^{15}$ Similarly, workers in the No History condition with one employer also exerted higher effort on average than those who

rule out that firms would strategically separate from long-term employees in period 16 just to be able to re-hire them in period 17.

${ }^{14}$ Our sample yields 98.6 percent power to detect a medium standardized effect in mean differences $(d=0.5$ (Cohen 1969)) between workers in the two treatments at $p<0.05$, using a Mann-Whitney $\mathrm{U}$ test (calculated using the software G*Power (Faul et al. 2007)).

${ }^{15}$ Since observations are not independent within markets we use a cluster-robust version of the MWU test (see Datta and Satten 2005). 
changed jobs more frequently (9.2 for one employer vs. 5.9 for six employers; $p<0.001$, MWU). Hence, regardless of whether work histories are available, workers who act more cooperatively and reliably are also those with fewer employment changes.

Figure 1: Voluntary Effort and Number of Employers

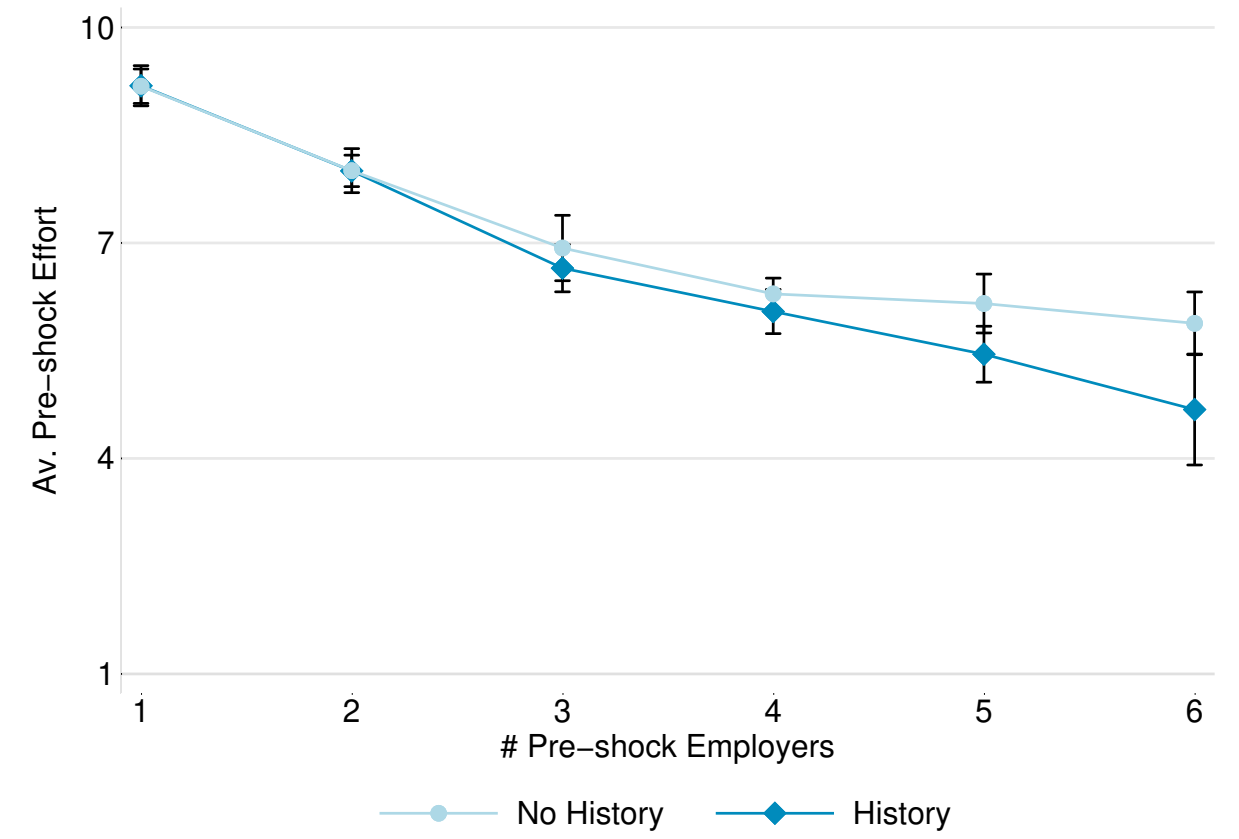

Average effort exerted by workers in periods 1 through 16 in relation to the number of different employers they had during that phase (minimum possible effort is 1). The unit of observation is a worker. Error bars indicate standard errors of the mean, calculated using 1000 bootstrap pseudo-samples, accounting for clustering at the labor market level. There is a negative relationship between effort exerted in periods 1 to 16 and the number of employers workers had during that phase.

A regression analysis confirms this non-parametric result (see Online Appendix Table A.1). We find that a one unit increase in average pre-shock effort is associated with a 0.36 (0.34) decrease in the number of pre-shock employers in the History (No History) condition (both $p<0.001$, t-tests). These two coefficients are not significantly different from each other.

\section{Result 1 (Employment history and effort)}

Frequent job changes are indicative of lower effort provision. This relationship holds for 
workers in both the History and No History conditions.

\section{Do firms prefer workers with stable employment?}

Figure 2 indicates that firms indeed use workers' employment histories to screen for higheffort workers. In period 17, workers with one pre-shock employer receive $84 \%$ more private offers in the History compared to the No History condition ( $p=0.007, \mathrm{MWU})$. And while the number of offers drops sharply in the History condition with the number of pre-shock employers, we observe no such trend in the No History condition.

Figure 2: Private Job Offers in Period 17

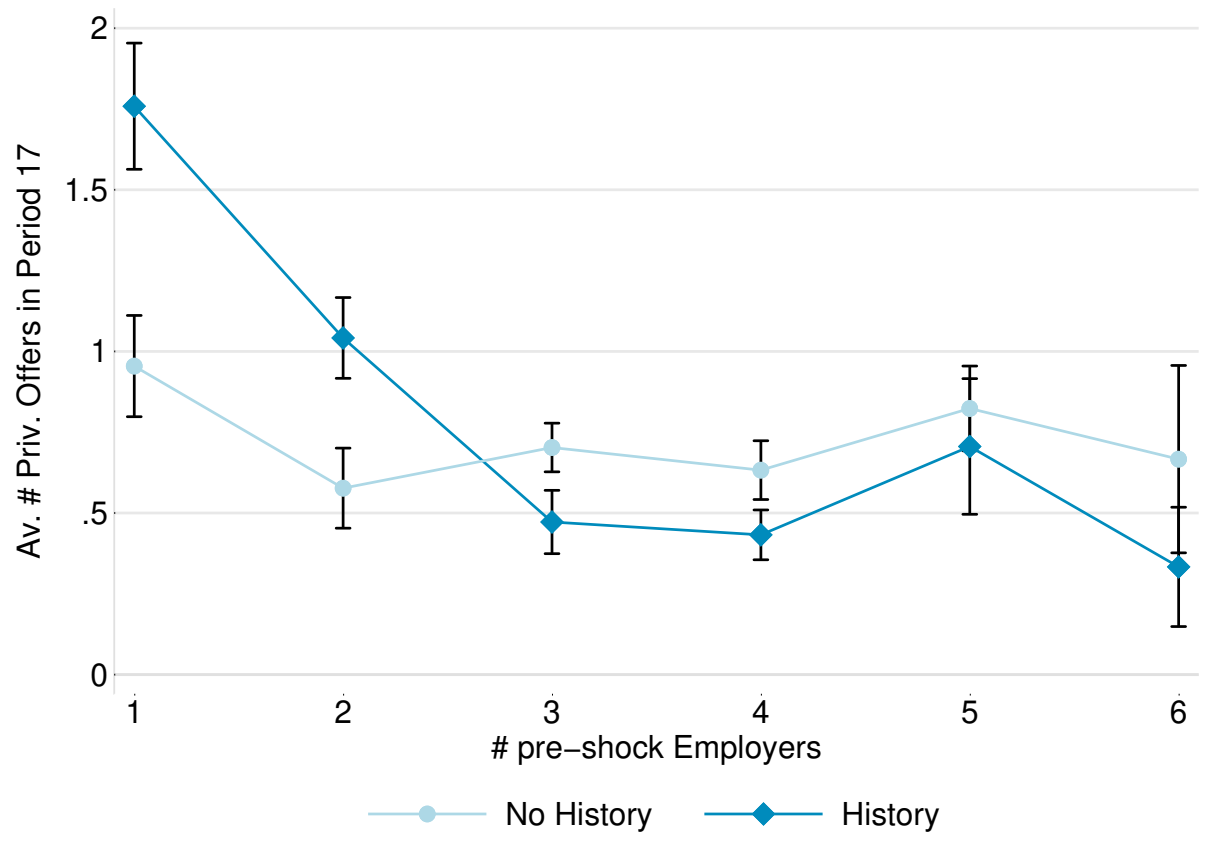

Average number of private employment offers that workers receive from firms at the beginning of period 17 (i.e., immediately after the employment shock) as a function of the number of different employers that workers had before the shock (periods 1 to 16). The unit of observation is a worker. Error bars indicate standard errors of the mean calculated using 1000 bootstrap pseudo-samples, accounting for clustering at the labor market level. In the No History condition, where firms rely solely on own information from their previous employment relations with workers, there is almost no effect of number of previous employers. In the History condition, where firms can observe all workers' employment histories before the shock, there is a pronounced negative effect of the number of previous employers. 
The regression analysis in Table 2 estimates the relationship between the frequency of job changes and employability while controlling for prior unemployment spells. Specifically, we estimate a regression model of the following form:

$$
y_{i}=\alpha+\beta_{1}\left(N_{i}-1\right)+\beta_{2} U_{i}+\varepsilon_{i m} .
$$

We regress the number of private offers received by an employee in period $17, y_{i}$, on the number of pre-shock employers minus 1 (i.e., $N_{i}-1$ ). Thus, the constant reflects the number of private offers obtained by a worker with one pre-shock employer. ${ }^{16}$ We additionally control for the number of periods unemployed before the shock, $U_{i}$, which is also observable for prospective employers in the History condition. Columns 1 and 2 look at the two conditions separately. Column 1 shows that, controlling for unemployment spells, each additional employer before the shock significantly reduces the number of private offers in period 17 by 0.219 in the History condition ( $p=0.005$, t-test). By contrast, column 2 shows that in the No History condition-where information about job changes is private information - the coefficient of the number of additional employers is close to zero and statistically insignificant ( $p=0.936$, t-test). In column 3 , we pool observations from both treatments and include a dummy for the History treatment, as well as its interaction with the number of pre-shock employers. The positive and significant coefficient for History indicates that a worker in the History condition with only one previous employer receives 0.64 more private offers $(p=0.002$, t-test). The results confirm that the coefficient for the number of additional employers is significantly lower in the No History than in the History condition $(p=0.004$, t-test).

There is a positive correlation between number of pre-shock employers and number of pre-shock periods unemployed, $\rho=0.29 .{ }^{17}$ However, unlike switching employers, being

\footnotetext{
${ }^{16}$ No worker was unemployed in all 16 pre-shock periods.

${ }^{17}$ Regression analysis shows that one more employer is associated with 0.45 more periods of unemployment in the No History condition and 1.03 more periods in the History condition. The difference in the association is significant ( $p=0.035$, accounting for clustering at the market level), suggesting that workers who switch employers more often already have a harder time finding employment in the pre-shock phase (regression output omitted).
} 
previously unemployed is significantly related to receiving job offers in both conditions. Specifically, we find that every additional period of unemployment reduces the number of private offers by 0.074 in the History condition ( $p=0.009$, t-test, see column 1) and 0.050 in the No History condition $(p=0.023$, t-test, see column 2$)$. The negative relationship between unemployment and employability tends to be weaker in the No History condition $(p=0.090$, t-test, see column 4$)$, and is partly due to firms not making private offers in period 17 to workers they had "fired" before the shock. ${ }^{18}$ Thus, the correlation between number of employers and periods unemployed means that omitting number of employers inflates the coefficient for periods unemployed. Finally, column 5 shows that the relationship between number of previous employers and number of job offers in the History condition is robust to controlling for treatment-specific effects of unemployment spells.

Because firms screen for workers with stable job histories, workers with frequent employment changes achieve lower earnings. Our experimental design allows us to follow workers for the 14 periods after the unemployment shock (i.e., periods 17 to 30). The "lifetime" loss in earnings for workers with unsteady pre-shock job histories in the History condition is sizable: workers with five or six pre-shock employers earned, on average, 261 ECU, while average earnings for workers with one or two pre-shock employers are 428 ECU, or about $64 \%$ more $(p<0.001, \mathrm{MWU})$. In the No History condition, the difference in earnings between these two groups of employees is much smaller (312 ECU vs. 360 ECU, $p<0.001, \mathrm{MWU}){ }^{19}$

\section{Result 2 (Employment history and job outcomes)}

When employment histories are available, workers with fewer previous employers receive more private job offers. This relationship is much weaker when employment histories are

\footnotetext{
${ }^{18}$ In additional regression analysis, we find that firms condition offers on prior experience with a worker and that this relationship is stronger in the No History condition. This highlights the possibility that firms may try to rely on other available information regarding individuals' work attitude. However, despite this relationship, which works against our hypothesis by providing an alternative informational channel in the History condition, our hypothesized relationships persist.

${ }^{19}$ See also the regression analysis in Table A.2 in the Online Appendix.
} 
Table 2: Regression analysis of private job offers in Period 17

\begin{tabular}{|c|c|c|c|c|c|}
\hline Condition & $\begin{array}{c}(1) \\
\text { History }\end{array}$ & $\begin{array}{c}(2) \\
\text { No History }\end{array}$ & $\begin{array}{c}(3) \\
\text { Pooled }\end{array}$ & $\begin{array}{c}(4) \\
\text { Pooled }\end{array}$ & $\begin{array}{c}(5) \\
\text { Pooled }\end{array}$ \\
\hline \# Employers & $\begin{array}{l}-0.219^{* * *} \\
(0.068)\end{array}$ & $\begin{array}{r}-0.005 \\
(0.056)\end{array}$ & $\begin{array}{r}-0.027 \\
(0.051)\end{array}$ & & $\begin{array}{r}-0.005 \\
(0.055)\end{array}$ \\
\hline \# Periods Unemployed & $\begin{array}{l}-0.074^{* * *} \\
(0.025)\end{array}$ & $\begin{array}{l}-0.050^{* *} \\
(0.020)\end{array}$ & & $\begin{array}{l}-0.051^{* *} \\
(0.019)\end{array}$ & $\begin{array}{l}-0.050^{* *} \\
(0.020)\end{array}$ \\
\hline History & & & $\begin{array}{l}0.644^{* * *} \\
(0.192)\end{array}$ & $\begin{array}{c}0.420^{* *} \\
(0.205)\end{array}$ & $\begin{array}{c}0.673^{* * *} \\
(0.239)\end{array}$ \\
\hline History $\times \#$ Employers & & & $\begin{array}{l}-0.269^{* * *} \\
(0.086)\end{array}$ & & $\begin{array}{l}-0.215^{* *} \\
(0.087)\end{array}$ \\
\hline History $\times$ \# Periods Unempl. & & & & $\begin{array}{l}-0.052^{*} \\
(0.030)\end{array}$ & $\begin{array}{r}-0.024 \\
(0.031)\end{array}$ \\
\hline Constant & $\begin{array}{l}1.639^{* * *} \\
(0.193)\end{array}$ & $\begin{array}{l}0.965^{\text {*** }} \\
(0.147)\end{array}$ & $\begin{array}{l}0.768^{* * *} \\
(0.121)\end{array}$ & $\begin{array}{l}0.957^{* * *} \\
(0.106)\end{array}$ & $\begin{array}{l}0.965^{* * *} \\
(0.145)\end{array}$ \\
\hline R-squared & 0.245 & 0.035 & 0.114 & 0.124 & 0.173 \\
\hline $\mathrm{N}$ & 170 & 160 & 330 & 330 & 330 \\
\hline
\end{tabular}

OLS regressions, standard errors in parentheses, adjusted for clustering at the labor market level, using White sandwich estimators. Unit of observation: worker.

Significance levels: ${ }^{*} \mathrm{p}<0.1, * * \mathrm{p}<0.05, * * * \mathrm{p}<0.01$.

Dependent variable: number of private offers to worker after the shock (period 17).

Independent variables: Constant: the baseline is a worker in the (No) History condition who was continuously employed by the same firm for all 16 periods before the shock. "History:" dummy for History treatment condition; "\# Employers:" number of additional pre-shock employers; "\# Periods Unempl.:" number of pre-shock periods the worker was unemployed.

not available. This negative effect of having many employers on employability translates into lower future earnings.

Beyond employability and earnings, screening via job history has broader labor market implications. Figure 3 shows that the availability of employment histories influences the duration of employment and unemployment spells. On average, employment relations last longer when employment histories are available ( 2.4 vs. 3.2 periods, $p=0.002$, MWU) and workers remain unemployed for longer stretches (1.9 vs. 2.3 periods, $p=0.001$, MWU). Further analysis reveals that this is driven by both the demand and supply sides of the labor market. ${ }^{20}$

\footnotetext{
${ }^{20}$ Across the experiment, firms are more likely to make job offers to their current workers in the History than in the No History condition $(p<0.001$, t-test $)$ and workers are more likely to accept offers from their current employers $(p=0.028$, t-test). The p-values come from OLS regressions of the respective variables on a treatment dummy with cluster-robust standard errors at the labor market level. We also find that observable job histories make private reputation portable: firms in the History condition are more willing to make offers to workers they had not employed previously. In period 17, only $38 \%$ of employed workers had previously worked for the same firm in the History condition, while in the No History condition firms hired workers that they had employed before in $68 \%$ of cases. OLS regressions confirm that this difference is statistically significant $(p=0.006$, t-test).
} 


\section{Result 3 (Labor market frictions)}

Employment relationships and unemployment spells last longer when job histories are publicly observable.

Figure 3: Hysteresis with Job Market History
(A) Employment
(B) Unemployment

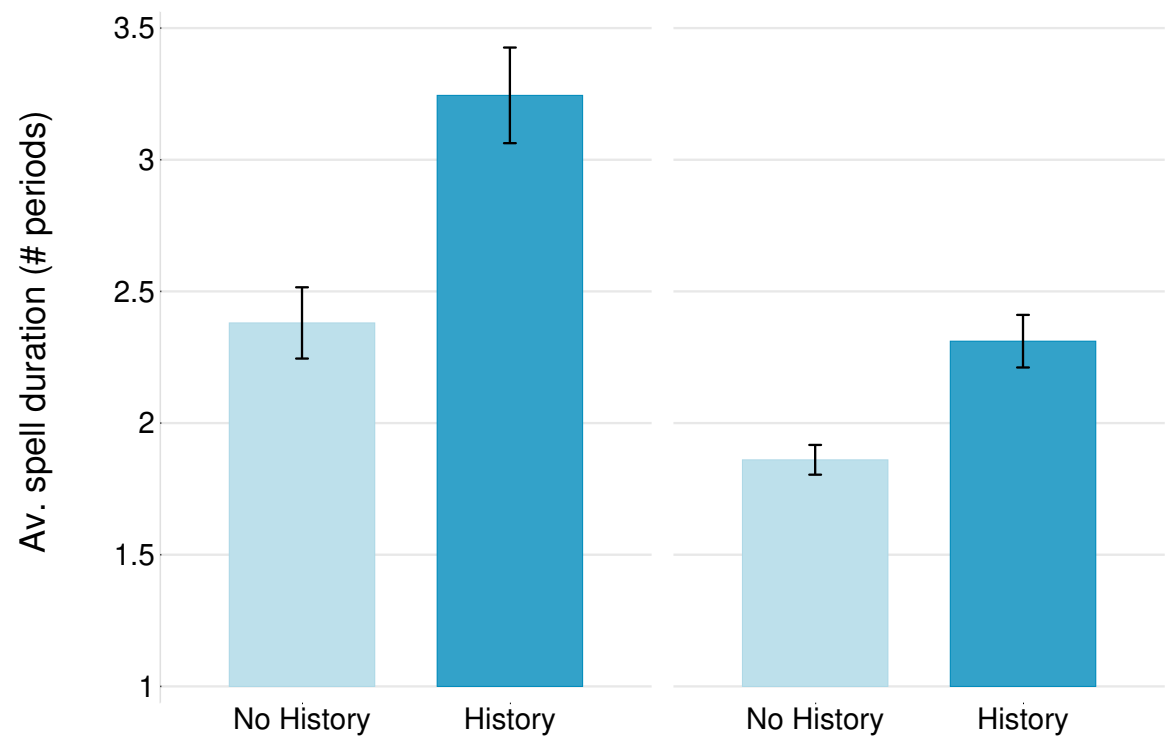

Average duration of employment and unemployment spells, in number of periods, across conditions (minimum spell duration is 1 period). The unit of observation is a labor market. Error bars represent standard errors of the mean. Panel A shows that the average employment spell is about $36 \%$ longer in treatment History relative to No History. Panel B shows that the availability of employment histories increases unemployment spells by $24 \%$.

\section{Field Experiment}

Our laboratory experiment suggests that frequent job changes provide a negative signal of prospective employees' work attitude. The lab study also shows that employers use this information, if available, to determine which workers to seek out for employment. We now examine whether these results hold in an actual labor market with real firms. To this 
end, we conducted a field experiment using the correspondence method, a well-established approach to study employer preferences in hiring (e.g., Riach and Rich 2002; Bertrand and Mullainathan 2004; Carlsson and Rooth 2007; Pager, Western, and Bonikowski 2009; Oreopoulos 2011). Specifically, we applied to a large number of job openings using fictitious applicants and then measured whether the prospective employers called back the applicants for a job interview. We exogenously varied the number of previous jobs that our candidates held to examine whether this would influence the probability of a callback.

We conducted the field experiment in two waves. The first wave took place between May and June 2012. The second wave was conducted one year later, from April to June 2013, to address possible concerns about one particular design feature in the first wave. We sent out a total of 1,680 applications for positions in the German-speaking part of Switzerland (680 in the first wave and 1,000 in the second wave). Our design follows previous correspondence studies (e.g., Bertrand and Mullainathan 2004; Kroft, Lange, and Notowidigdo 2013), by focusing on low- and middle-skill jobs, such as administrative support, clerical services, customer services, sales management, project and product management, accounting and entry-level positions in marketing and consumer finance. ${ }^{21} \mathrm{We}$ selected these occupations as ones in which work attitude is likely to play an important role in job performance and desirability to employers, in contrast with, for example, the hiring of doctors or computer programmers, where skill may be more important. Over two waves of data collection, we surveyed all administrative and clerical job ads posted on mainly three major job search websites. To obtain reasonably high callback rates, we focused on job postings that were no older than ten days and that offered a position in the broader area of Zurich or adjacent cantons (i.e., reasonably close to the applicants' home address).

\footnotetext{
${ }^{21}$ Administrative and clerical jobs alone account for about $11 \%$ of Switzerland's total workforce (Swiss Federal Statistical Office 2008).
} 


\section{The resumes}

For each wave, we created four identities (two male and two female) for the fictitious job applicants. We used names from a list of the most common first and family names in Switzerland to avoid effects of ethnic discrimination, and employed photos from students who gave us their permission to use them for the study. To track responses, we gave each identity a unique home address, email address, and cell phone number. ${ }^{22}$ We took great care to make the resumes look authentic and appealing. To this end, we consulted Human Resources professionals and used templates from the Swiss Association of Commercial Employees and related websites.

We sent out two applications for every open position. The pairs of applications described virtually identical applicants in all observable characteristics, except for the frequency of job changes. Both candidates were 26 years old, reflecting a natural age for the positions to which the applications were sent, and well-qualified, as they had a diploma in commercial studies with high grades. The young age of applicants in our study reflects high job search rates for this age group and corresponds to the ages used in earlier research (Kroft, Lange, and Notowidigdo 2013; Eriksson and Rooth 2014; Deming et al. 2016). Both applicants had eight years of work experience in exactly the same job functions. To differentiate the two resumes, we described the functions using different terms (e.g., human resources vs. personnel management) and changed the order in which the functions appeared on the resumes. Both applicants were currently employed when we sent out the applications. We further gave both a set of complementary qualities that employers typically desire for commercial workers, such as relevant computer and language skills. To minimize suspicion, we used a different formatting and layout for the two resumes. We counterbalanced the two formatting schemes across treatments.

\footnotetext{
${ }^{22}$ Incoming calls were automatically redirected to a voice mail box. Email addresses had different providers to minimize suspicion. To collect responses by postal mail we used real postal addresses and tagged the letter boxes with the corresponding names. However, only about $2 \%$ of the employers contacted the applicants via postal mail.
} 


\section{Treatments}

For each identity, we implemented a version of the resume with continuous employment at a single firm ("One Employer" condition) and a version with comparable experience but four different firms ("Four Employers" condition). After a degree in commercial education, the candidate made horizontal moves between four firms every twenty to twenty-four months. In contrast, the applicant with the One Employer resume had spent his or her entire post-education career at the same company. ${ }^{23}$ Both resumes exhibited a total of eight years of work experience in exactly the same departments (i.e., administration, accounting, human resources, customer service, and purchasing). ${ }^{24}$

For each job ad, we sent a Four Employers and a One Employer resume. We randomized which of the two applicants was assigned the Four and One Employer resume, respectively, and then submitted both resumes, in randomized order, a couple of hours apart. Both had the same gender, which was determined at random unless an employer explicitly asked for candidates of a particular gender.

In the first wave, the Four Employers resumes had short gaps between jobs. Although short breaks between jobs are the norm for young workers in Switzerland, they could potentially affect callback rates because employers may consider them as unemployment spells, which in turn may signal low productivity (Oberholzer-Gee 2008; Kroft, Lange,

\footnotetext{
${ }^{23}$ To provide a sense of how frequent having one and four prior employers is for workers in the age range of our hypothetical job applicants, Online Appendix Figures A.2 and A.3 report the cumulative number of prior employers at age 26 for workers in the National Longitudinal Survey of Youth 1997 (NLSY97). For young workers in the US, 1 and 4 prior employers tend to be low, though not unusual numbers. Unfortunately, we were unable to obtain data for a comparable longitudinal panel in Switzerland. However, the rotating Swiss Household Panel (SHP) provides year-on-year job changes for young people in Switzerland, which we compare to the US (Online Appendix Figure A.4). This comparison reveals that the yearly rate of job changes for young workers between the ages of 20 and 26 is approximately 25 to 30 percent, which is slightly lower than in the US. Moreover, Figure A.5 reveals that the yearly job change rates do not differ greatly for different categories of workers in Switzerland. We interpret this analysis, cautiously, as indicating that the job histories of our hypothetical applicants are reasonable for the Swiss labor market.

${ }^{24}$ The companies were chosen from a list of employers that offer commercial positions from a vocational counseling website. We focus only on horizontal job changes, not vertical. Upward job mobility may be seen as a signal of positive traits, such as varied experience, larger professional networks, and greater ambition, and thus counteract the negative effects on perceived work attitude. See, also, the references in footnote 5 .
} 
and Notowidigdo 2013; Eriksson and Rooth 2014). We therefore removed the gaps from the Four Employers' work history in the second wave.

\section{Measuring callbacks}

We recorded all incoming responses within ten weeks after submitting the applications; however, most employers contacted the applicants within two weeks. Because we are interested in whether the employers exhibit a preference for one candidate, we define a callback as an explicit request for an interview or a message stating that one of the applicants is shortlisted for an interview. ${ }^{25}$ Two research assistants who were blind to the experimental conditions coded the responses according to these pre-defined rules. To minimize the inconvenience caused to the employers, we declined interview invitations within 24 hours. $^{26}$

\subsection{Results of the Field Experiment}

In total, we sent 1,680 applications to 840 job vacancies in a broad range of industries (see Table A.3 in the Online Appendix). ${ }^{27}$ Most ads were for jobs in private limited liability companies $(87.7 \%)$, followed by public employers or NGOs $(8.8 \%)$, and organizations of other legal forms (3.5\%, e.g., single proprietors or cooperatives). $75.4 \%$ looked for fulltime employees (i.e., at least four days a week). ${ }^{28}$ Because we used a within-subjects design-i.e., each prospective employer received a One Employer and a Four Employer resume - our sample of firms is, by construction, balanced across treatments.

\footnotetext{
${ }^{25}$ In this regard, we follow earlier correspondence studies by defining interview requests as our dependent measure (e.g., Bertrand and Mullainathan 2004; Eriksson and Rooth 2014; Kroft, Lange, and Notowidigdo 2013). It is reasonable to expect that an invitation for an interview reflects an employer's hiring preference with less noise than, for instance, requests for additional information, and that differences in interview rates translate into differences in hiring rates.

${ }^{26}$ All our studies were approved by the Human Subjects Committee of the Faculty of Economics, Business Administration, and Information Technology of the University of Zurich.

${ }^{27}$ Our sample size allows us to detect a standardized effect size (Cohen's $d$ ) of 0.137 at a power of 0.8 and p-value of 0.05. Our study is thus powered to detect a "small" effect size $(\mathrm{d}=0.2)$, as well as effect sizes comparable to those observed in most related earlier work employing the correspondence method.

${ }^{28}$ The sample includes job openings placed by employment agencies $(16.2 \%)$; the results do not change if we exclude these observations from the analysis.
} 
We obtained callbacks for $17.1 \%$ of the applications; $57.9 \%$ of the applications were immediately rejected, $14.6 \%$ remained unanswered and $10.4 \%$ received requests that more documents would be needed (without receiving an interview invitation or being shortlisted). The average (median) response time was 10.2 (6) days. Most responses came in by email ( $85 \%)$, followed by phone call $(13 \%)$, and postal mail $(2 \%)$.

The results from the first wave show that the Four Employers profile led to a substantially lower callback rate (see Panel A in Figure 4). While the Four Employers resume had a callback rate of $16.8 \%$, the rate was $23.2 \%$ for the One Employer condition, i.e., $40 \%$ higher. This difference is statistically significant $\left(p=0.003\right.$, McNemar test) ${ }^{29}$

Figure 4: Job changes and employability

(A) Wave 2012

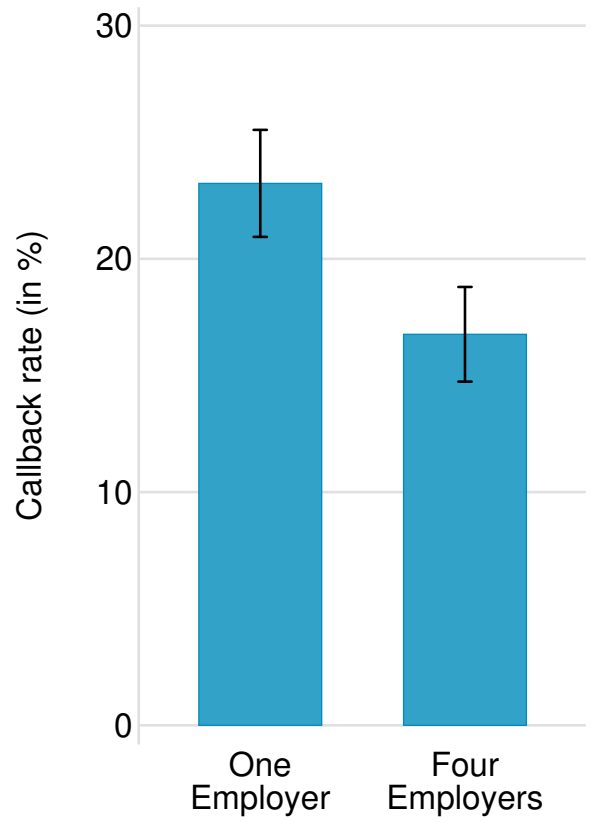

(B) Wave 2013

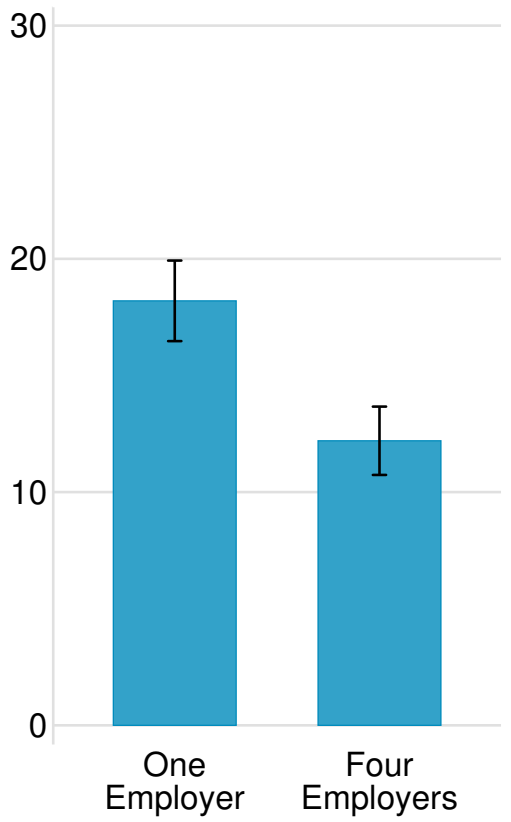

Error bars indicate standard errors of the mean. Panel A displays average callback rates by treatment for the 2012 wave. Panel B shows the results for the 2013 wave where the Four Employers resume did not contain any employment gaps between job changes.

\footnotetext{
${ }^{29}$ We use the non-parametric McNemar test for paired observations which compares how often one profile is preferred over the other (see Siegel and Castellan 1988).
} 
Panel B in Figure 4 shows that the results replicate in the second wave, when the Four Employers resume had no gaps between jobs. The treatment effect is similar to the one in the 2012 wave: the callback rate is about 50\% higher in the One Employer relative to the Four Employers condition (18.2\% vs. $12.2 \%, p=0.001$, McNemar test) ${ }^{30}$

Our treatment effect is sizable across both waves compared to other correspondence studies. For example, the standardized effect size (i.e., Cohen's $d$ ) in our study is similar in magnitude to the difference in callback rates that Kroft, Lange, and Notowidigdo (2013) found between applicants with one and eight months of unemployment. It is also similar to the difference between applicants with white- vs. black-sounding names as reported in Bertrand and Mullainathan (2004). ${ }^{31}$

A regression analysis corroborates the preceding non-parametric results. Specifically, we estimate the following linear probability model:

$$
y_{i j}=\alpha+\beta_{1} * N_{i j}+\beta_{2} * \mathbf{X}_{i j}+\beta_{2} * \mathbf{Z}_{j}+\epsilon_{i j} .
$$

The dependent variable $y_{i j}$, indicating whether applicant $i$ received a callback for vacancy $j$, is regressed on a dummy variable, $N_{i j}$, for the Four Employers treatment. We control for month of the year, gender of the applicant, gender of the recruiting manager (i.e., contact person) and gender match between the two. We also add dummies for job ads with above

\footnotetext{
${ }^{30}$ Overall, the callback rate in both treatments tends to be lower in 2013 than in 2012 ( $p=0.062$ for Four Employer and $p=0.075$ for One Employer, $\chi^{2}$-tests). One possible reason is that the applicants faced tougher labor market conditions in 2013. Monthly regional labor market statistics (SECO 2013) show that the average number of candidates per job increased from 8.8 to 10.4, and that the local unemployment rate rose from 2.7 to 2.8 between the first and the second wave. An occupation-specific but less direct indicator of labor market conditions is the average response time in our field experiment, which we can use as a proxy for the number of applications the HR recruiters had to assess at that time. In line with the aggregate labor market data, we find a significant increase in average response time from 7.7 work days in 2012 to 8.7 work days in 2013 ( $p=0.025$, MWU). As shown in the regression analysis, the effect of multiple previous employers is neither more nor less pronounced when workers compete for fewer jobs.

${ }^{31}$ Kroft, Lange, and Notowidigdo (2013) found that callback rates dropped from roughly $7 \%$ to $4 \%$. With a standard deviation of 0.212 , this corresponds to a standardized mean effect (i.e., Cohen's $d$ ) of 0.142. Bertrand and Mullainathan (2004) found callback rates of $9.7 \%$ and $6.4 \%$ for white and blacksounding names, respectively. The standard deviation in callbacks was 0.272 , implying a Cohen's $d$ of 0.121. In our study, pooling both waves, we found a $20.2 \%$ callback rate for the One Employer condition and a $14.0 \%$ callback rate for the Four Employer condition. The standard deviation in callbacks was 0.377 , resulting in a Cohen's $d$ of 0.164 .
} 
median expected wages (estimated using job titles on Switzerland's biggest job search platform), employment agencies and part-time positions, as well as the firms' industry and legal form. Finally, we include the (log) driving distance to the workplace and monthly local labor market conditions (i.e., the number of applicants per open position and the employment rate at the cantonal level). The vectors $\mathbf{Z}_{i}$ and $\mathbf{X}_{i j}$ represent the control variables measured at the vacancy level and those that vary within vacancies, respectively, and $\epsilon_{i j}$ is the idiosyncratic error term. We report OLS estimates and correct the standard errors for clustering at the vacancy level.

Table 3: Regression analysis of job changes and employability

\begin{tabular}{|c|c|c|c|c|c|c|}
\hline \multirow[t]{2}{*}{ Dependent variable } & \multicolumn{6}{|c|}{ Callback $=1$} \\
\hline & (1) & $(2)$ & (3) & (4) & (5) & (6) \\
\hline Four Employer & $\begin{array}{l}-0.062^{* * *} \\
(0.014)\end{array}$ & $\begin{array}{l}-0.060^{* * *} \\
(0.018)\end{array}$ & $\begin{array}{l}-0.061^{* * *} \\
(0.018)\end{array}$ & $\begin{array}{l}-0.061^{\text {*** }} \\
(0.018)\end{array}$ & $\begin{array}{l}-0.060^{* * *} \\
(0.018)\end{array}$ & $\begin{array}{l}-0.073^{* * *} \\
(0.019)\end{array}$ \\
\hline Four Emp. $\times$ wave 2012 & & $\begin{array}{r}-0.005 \\
(0.028)\end{array}$ & $\begin{array}{r}-0.005 \\
(0.028)\end{array}$ & $\begin{array}{r}-0.005 \\
(0.028)\end{array}$ & $\begin{array}{r}-0.005 \\
(0.028)\end{array}$ & $\begin{array}{r}0.001 \\
(0.029)\end{array}$ \\
\hline Wave 2012 & & $\begin{array}{c}0.050^{*} \\
(0.029)\end{array}$ & $\begin{array}{r}0.040 \\
(0.029)\end{array}$ & $\begin{array}{r}0.032 \\
(0.030)\end{array}$ & $\begin{array}{r}0.037 \\
(0.031)\end{array}$ & $\begin{array}{r}0.041 \\
(0.030)\end{array}$ \\
\hline Industry experience & & & & & & $\begin{array}{c}0.062^{* *} \\
(0.031)\end{array}$ \\
\hline Constant & $\begin{array}{l}0.202^{* * *} \\
(0.014)\end{array}$ & $\begin{array}{l}0.182^{* * *} \\
(0.017)\end{array}$ & $\begin{array}{c}0.492^{* * *} \\
(0.156)\end{array}$ & $\begin{array}{c}0.334^{* *} \\
(0.143)\end{array}$ & $\begin{array}{r}0.266 \\
(0.206)\end{array}$ & $\begin{array}{r}0.258 \\
(0.205)\end{array}$ \\
\hline Additional controls? & & & & & & \\
\hline Month & & & & Yes & Yes & Yes \\
\hline Gender/gend. match & & & Yes & & Yes & Yes \\
\hline Firm/job character. & & & Yes & & Yes & Yes \\
\hline Driving distance & & & Yes & Yes & Yes & Yes \\
\hline Labor market & & & & Yes & Yes & Yes \\
\hline Observations & 1680 & 1680 & 1680 & 1680 & 1680 & 1680 \\
\hline$F$ & 20.328 & 8.271 & 5.466 & 5.488 & 5.248 & 4.716 \\
\hline Prob $>F$ & 0.000 & 0.000 & 0.000 & 0.000 & 0.000 & 0.000 \\
\hline
\end{tabular}

OLS regressions, cluster-robust standard errors at the job ad level.

Dependent variable: Dummy indicating a callback.

Independent variables: "Four Employers:" dummy for Four Employers resume; "Wave 2012:" dummy for the first wave of the study (in 2012); "Industry experience:" dummy whether the applicant had previous work experience in the corresponding industry; "Month:" dummies for month when the application was submitted; "Gender/gender match:" dummies for the gender of the applicant and recruiting manager, and the corresponding interaction term between the two; "Firm/job characteristics:" dummies for job ads with above median expected wages (source: jobs.ch), legal form, employment agency, part-time jobs, and industry fixed effects; "Driving distance:" log of the distance between home and work address (in meters and assuming traveling by car using Google Maps); "Labor market:" monthly local unemployment rate and the number of applicants per open position. Both labor market variables are normalized to a mean of zero and a standard deviation of one (statistics from State Secretariat for Economic Affairs (SECO)).

Significance levels: ${ }^{*} \mathrm{p}<0.1,{ }^{* *} \mathrm{p}<0.05,{ }^{* * *} \mathrm{p}<0.01$. 
Table 3 presents regression results for various combinations of control variables. Column 1 shows the results without control variables. We find a significant $6.2 \%$ point reduction in the callback rate in the Four Employers relative to the One Employer treatment $\left(p<0.001\right.$, t-test). ${ }^{32}$ In Column 2 we test whether the treatment effect is significantly different between the two waves by including a dummy for the 2012 wave and its interaction with treatment Four Employers. The interaction effect is small and statistically insignificant ( $p=0.867$, t-test), suggesting that the treatment effect is stable across waves. Columns 3 through 5 indicate that the Four Employers effect is robust in magnitude and significance if we control for a variety of background variables.

\section{Result 4 (Employment history and employability in the field)}

Applicants with more frequent job changes are significantly less likely to receive callbacks for job interviews. The effect persists regardless of whether resumes include short employment gaps between jobs.

Although we find a consistently negative effect of the Four Employers resume, we want to emphasize that our results do not imply that more frequent job changes will always reduce employability. A higher frequency of job changes can, in principle, also signal desirable qualities, such as that a worker gained more transferable human capital due to more diverse work experiences (Mincer 1958; Becker 1962). This is particularly true for vertical job changes, which we do not consider in our experiment. Yet, one way to examine this in our context is to look at relevant industry experience. Job applicants with the Four Employers resume were, by design, more likely to have work experience in the industry of the prospective employer compared to those with only one previous employer ( $50 \%$ vs. $32.6 \%, p<0.001, \chi^{2}$-test). To explore the extent to which more diverse industry experience had a compensating positive effect on employability, Column 6 of

\footnotetext{
${ }^{32}$ The results are similar if we use a Probit model instead. The results are also similar, though weaker in magnitude and statistical significance, if we treat requests for additional documents as callbacks (see Table A.5 in the Online Appendix). This is consistent with our prior belief that requests for additional information are a noisier measure of employer preferences, as they potentially also include contacts by an administrator seeking to complete a file.
} 
Table 3 additionally includes a dummy variable, "Industry experience," reflecting whether the applicant has ever worked in the industry of the prospective employer. Industry experience significantly increases the probability of a callback by $6.2 \%(\mathrm{p}=0.043$, $\mathrm{t}$ test). Hence, job changes can increase the callback rate through a higher likelihood of relevant work experience. Importantly, however, the magnitude of the coefficient for the Four Employers treatment is approximately 22\% greater in Column 6 than in Column 5, where we do not control for industry experience. In other words, had the One and Four Employers candidates had similar levels of industry experience, employers would have discriminated even more strongly against the Four Employers candidate.

\section{Heterogeneity and robustness}

Finally, we explore several possible sources of heterogeneity in the effect of job changes on employability. First, we exploit variation of labor market conditions over time and regions (i.e., cantons) to study whether market tightness moderates the treatment effect. For this purpose we interact the Four Employers treatment variable with two monthly indicators of labor market conditions available at the cantonal level: the unemployment rate (ranging from 1.2 to 3.2 percent) and the number of applicants per vacancy (ranging from 3.7 to 30 applicants). ${ }^{33}$ We normalized both measures to have a mean of zero and a standard deviation of one. The first two rows in Panel A of Table 4 suggest that the treatment effect does not significantly vary with labor market tightness $(p=0.480$, and $p=0.123$, t-tests). In Row 3, we analyze whether the penalty for frequent job changes differs by the expected wage of the open positions. For this, we collected expected wages for all vacancies using data from Switzerland's biggest job search platform (jobs.ch), which provides average wages based on job titles. ${ }^{34}$ We created a dummy variable, "High wage," for job ads with above-median expected wages and included an interaction term

\footnotetext{
${ }^{33}$ Both measures are available from the State Secretariat of Economic Affairs (SECO 2013).

${ }^{34}$ The average expected wage for the job ads in our sample is $72,189 \mathrm{CHF}$ and ranges from 57,154 CH to 132,197 CHF. For cases where the job ads contained two job titles (e.g., accounting clerk / HR administration), we took the higher paid one; the results do not change if we select the lower paid title instead.
} 
with treatment Four Employers. While callback rates tend to be higher for higher paid jobs, the interaction effect is not significant ( $p=0.325$, t-test). If anything, the treatment effect tends to be larger for higher paid jobs. In Row 4, we restrict the sample to job ads where the estimated wage on jobs.ch is based on at least 50 observations. The coefficient, however, remains unchanged and insignificant ( $p=0.318$, t-test).

Table 4: Heterogeneous treatment effects

\begin{tabular}{|c|c|c|c|c|}
\hline & \multicolumn{4}{|c|}{ Panel A: Labor market tightness and wages } \\
\hline & Four Employers & Explanatory var. & Four Empl. $\times$ Expl.var. & Obs. \\
\hline \multirow[t]{2}{*}{ Applicants per vacancy } & $-0.069^{* * *}$ & -0.007 & 0.010 & 1680 \\
\hline & $(0.010)$ & $(0.016)$ & $(0.015)$ & \\
\hline \multirow[t]{2}{*}{ Unemployment rate } & $-0.091^{* * *}$ & 0.021 & 0.018 & 1680 \\
\hline & $(0.016)$ & $(0.012)$ & $(0.012)$ & \\
\hline \multirow[t]{2}{*}{ High wage } & $-0.059^{* * *}$ & $0.047^{*}$ & -0.027 & 1680 \\
\hline & $(0.019)$ & $(0.028)$ & $(0.028)$ & \\
\hline \multirow[t]{4}{*}{ High wage (min. $50 \mathrm{obs}$ ) } & $-0.059^{* * *}$ & $0.050^{*}$ & -0.028 & 1634 \\
\hline & $(0.019)$ & $(0.028)$ & $(0.028)$ & \\
\hline & \multicolumn{4}{|c|}{ Panel B: Industries } \\
\hline & Four Employers & Explanatory var. & Four Empl. $\times$ Expl.var. & Obs. \\
\hline \multirow[t]{2}{*}{ Service } & $-0.070^{* * *}$ & -0.135 & -0.012 & 1680 \\
\hline & $(0.017)$ & $(0.110)$ & $(0.037)$ & \\
\hline \multirow[t]{2}{*}{ Trade } & $-0.073^{* * *}$ & -0.054 & 0.001 & 1680 \\
\hline & $(0.016)$ & $(0.107)$ & $(0.040)$ & \\
\hline \multirow[t]{2}{*}{ Construction } & $-0.076^{* * *}$ & -0.133 & 0.047 & 1680 \\
\hline & $(0.015)$ & $(0.104)$ & $(0.047)$ & \\
\hline \multirow[t]{2}{*}{ Electro } & $-0.070^{* * *}$ & -0.036 & -0.017 & 1680 \\
\hline & $(0.017)$ & $(0.103)$ & $(0.038)$ & \\
\hline \multirow[t]{2}{*}{ Fiduciary } & $-0.074^{* * *}$ & -0.057 & 0.015 & 1680 \\
\hline & $(0.015)$ & $(0.106)$ & $(0.056)$ & \\
\hline
\end{tabular}

OLS regressions with cluster-robust standard errors at the job ad level (respectively, at the canton $\times$ month $\times$ wave level for the regressions that include interaction effects for "Applicants per vacancy" and "Unemployment rate"). The regression for "High wage (min. 50 obs)" contains only vacancies for which the estimated wage is based on at least 50 observations.

Dependent variable: Dummy indicating a callback.

Independent variables: "Four Employers:" dummy for Four Employers resume; "Unemployment rate:" monthly local unemployment rate; "Applicants per vacancy:" the number of applicants per open position; Both labor market variables are normalized to a mean of zero and standard deviation of one (source: statistics from State Secretariat for Economic Affairs (SECO)); "High wage:" dummy for job ads with above median expected average pay (source: jobs.ch); "Industry: service and admin", "Industry: trade", etc.: dummies for the largest industries in the sample (at least 50 job ads); All models control for the following variables in all regressions: "Wave:" dummy for the first wave of the study (in 2012); "Month:" dummies for month when the application was submitted; "Gender/gender match:" dummies for the gender of the applicants and recruiting managers, respectively, as well as the corresponding interaction term between the two; "Industry experience:" dummy for whether the applicant had work experience in the corresponding industry; 'Firm/job characteristics:" dummies for above median wage job, legal form, employment agency, part-time jobs, and industry fixed effects; "Driving distance:" log of the distance between home and work address (in meters and assuming traveling by car using Google Maps); "Labor market:" normalized monthly local unemployment rate and the normalized number of applicants per open position.

Significance levels: $* \mathrm{p}<0.1,{ }^{* *} \mathrm{p}<0.05, * * * \mathrm{p}<0.01$. 
We further assess the stability of the treatment effect across the biggest industries in our data set (i.e., we only consider industries for which we sent at least 50 pairs of applications). The results in Panel B of Table 4 show that none of the interaction effects reach statistical significance at the $5 \%$ level, suggesting that the negative effect of job changes is robust across diverse industries ( $p \geq 0.321$, t-tests). In Appendix Table A.8, we additionally test for heterogeneous treatment effects based on individual characteristicsthe applicants' gender and industry experience and the HR person's gender. None of the interactions between these characateristics and the Four Employer treatment is significant at the $5 \%$ level. $^{35}$

Overall, the treatment heterogeneity analysis indicates that the negative effect of frequent job changes on employability is stable across a wide range of individual and environmental characteristics. This suggests that our main result generalizes across multiple industries.

\subsection{Survey Experiment}

Although our correspondence study shows large effects of frequent job changes on a candidate's chances to be invited for a job interview, it does not tell us why the Four Employer candidates were less desirable. To get more insights about the underlying mechanism, we complement the correspondence study with a survey experiment with Human Resources (HR) professionals to obtain their perceptions of the candidates from the field experiment.

In the survey experiment, we were interested in whether those who make hiring decisions perceive the applicants with four previous employers as having lower work attitude than those with one previous employer. To answer this question, we recruited HR professionals at a job fair for graduating students that took place in Zurich in April 2014. At

\footnotetext{
${ }^{35}$ In Table A.9 in the Online Appendix we also tested for heterogeneous treatment effects with respect to various firm and job characteristics such as the firms' legal form, full/part-time positions, driving distance to the work place, job ads from employment agencies and positions outside of the canton of Zurich (i.e., the applicants' canton of residency). We find no statistically significant interactions effects for any of these variables $(p \geq 0.337$, t-tests).
} 
this event, mostly large companies from diverse industries (e.g., engineering, electronics, telecommunication and consulting) presented themselves to job seekers. ${ }^{36}$ Each company had its own booth, at which company representatives, including recruiters, were available for questions from prospective applicants. We approached each booth and asked whether the most experienced HR representative would be available for a short survey study. A total of $83 \mathrm{HR}$ professionals participated in that study.

Since we expected a smaller sample size than in our field experiment, we reduced the number of candidates to two male candidates drawn from the applicant pool in our field experiment. Each survey participant was shown a Four Employers and a One Employer resume, side by side. We randomized which of the two candidates would be the one with the greater number of job changes and counterbalanced the order (i.e., left or right) in which the candidates were presented.

In the survey, participants rated both candidates on ten characteristics using 7-point Likert scales, ranging from 1 "does not apply at all" to 7 "applies fully." 37 The characteristics can be broadly divided into task-related skills and experience (captured by the items "skilled," "experienced in commerce," and "multi-talented"), and work attitude ("able to work in teams," "willing to adapt," "perseverant," "honest," "reliable," "self-directed," and "goal-oriented"). We further asked participants how likely they would be to call back a candidate for an interview had the applicant applied at their firm, on a scale from 1 "very unlikely" to 7 "very likely."

The survey responses allow us to examine which qualities HR professionals associate with the different resumes from the field experiment, and which of these qualities are likely responsible for the difference in callback rates we find in the field experiment.

\footnotetext{
${ }^{36}$ See Online Appendix Table A.10 for descriptive statistics of our survey sample.

${ }^{37}$ The Online Appendix 3.1 provides a copy of the survey, translated from German to English.
} 


\subsection{Results of the Survey Experiment}

To distinguish task-related skills and experience from work attitude, we created an index for each of the two dimensions by averaging the ratings for a respondent's perception of the individual qualities within a particular dimension. Table A.12 in the Online Appendix presents the results for each individual characteristic. Figure 5 reveals that, relative to the One Employer condition, the Four Employers candidates score 0.40 points lower on work attitude $(p<0.001$, Wilcoxon signed rank test, henceforth denoted as WSR). By contrast, the difference in skill and experience between the two candidate profiles is small and statistically insignificant (0.03 points, $p=0.651$, WSR).

Figure 5: HR professionals' perceptions of One and Four Employers candidates

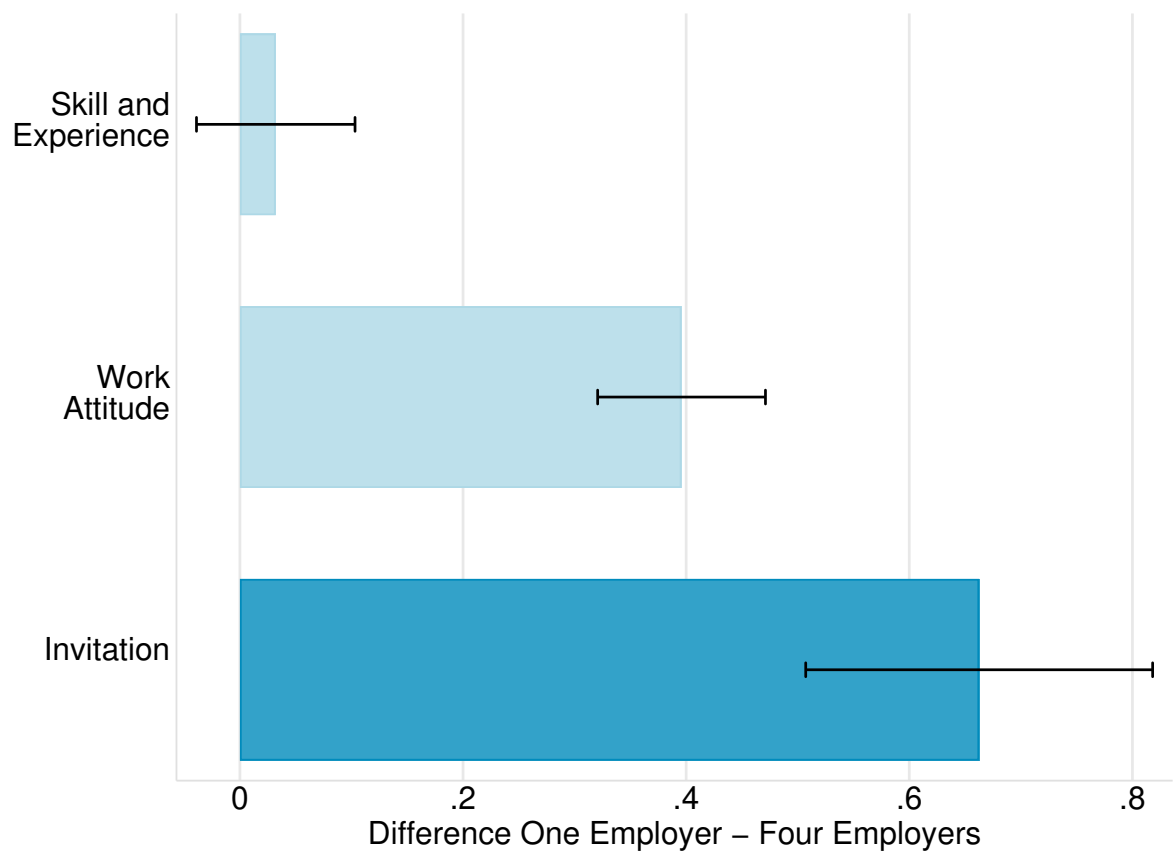

Average difference in ratings, based on a 7-point Likert scale, between the One Employer and Four Employers candidate. Error bars indicate standard errors of the mean.

Moreover, the HR professionals indicate that they would be more likely to invite the One Employer than the Four Employers candidate for a job interview ( $p<0.001$, WSR). We thus replicate, although with hypothetical choices, the finding that employers are more 
likely to invite candidates who change jobs less frequently for an interview. This confirms the key result from our field experiment with a separate sample of HR professionals. ${ }^{38}$

\section{Result 5 (HR professionals' perceptions of applicants)}

HR professionals perceive applicants with more frequent job changes as having poorer work attitude than those with fewer changes. The frequency of job changes does not affect the perception of task-related skills and experience. HR professionals prefer interviewing candidates with fewer job changes.

Table 5: Regression analysis of HR professionals' perceptions of the applicants

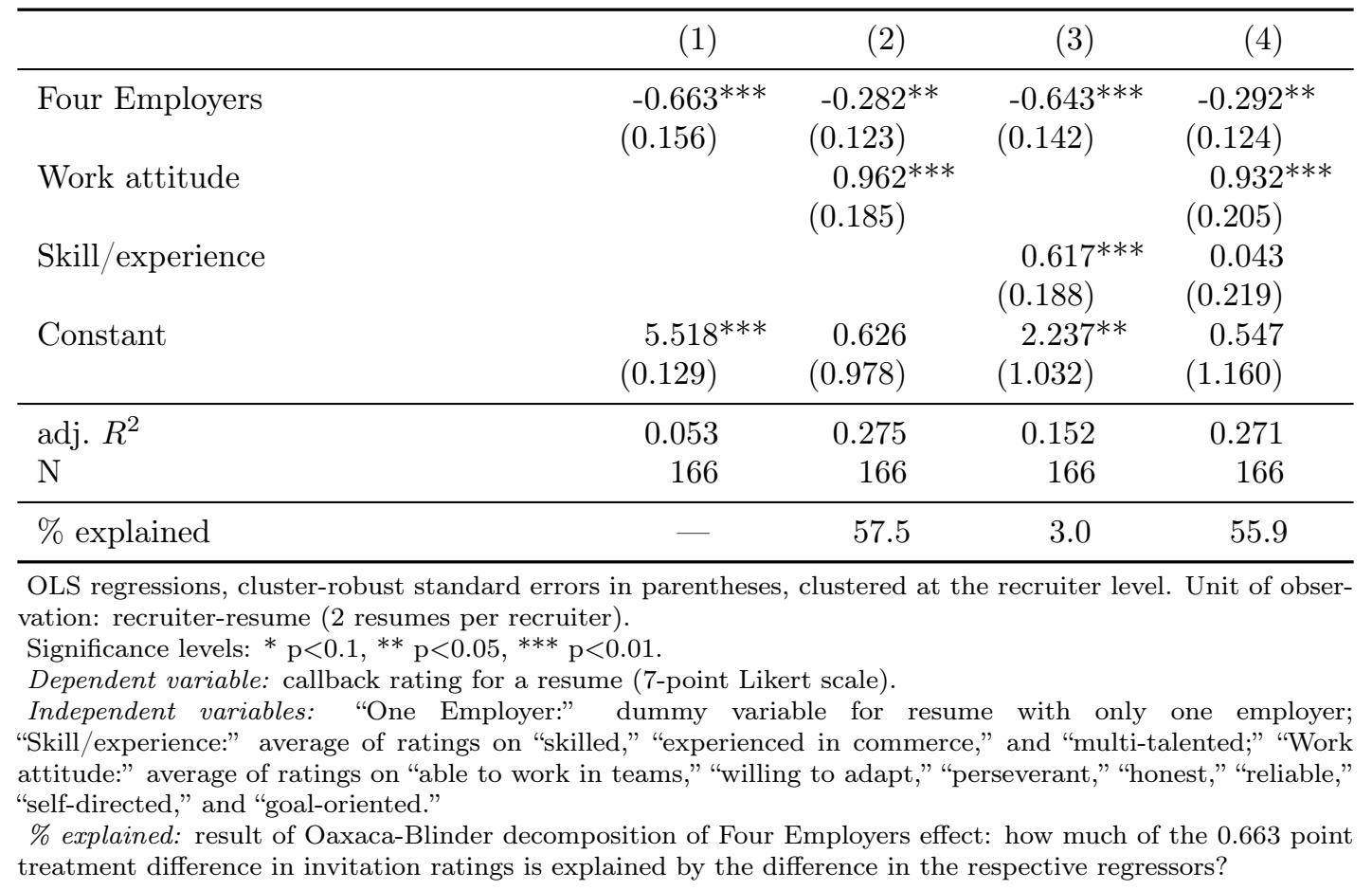

To assess the extent to which perceived differences in applicants' qualities can account for the difference in the callback rates, we estimate the following regression model:

$$
y_{i j}=\alpha+\beta_{1} * N_{i j}+\beta_{2} * A_{i j}+\beta_{2} * S_{i j}+\epsilon_{i j} .
$$

The dependent variable $y_{i j}$ is the stated likelihood of a callback (between 1 and 7) re-

\footnotetext{
${ }^{38}$ The results are similar if we divide the sample of HR professionals into those with more or less experience in hiring (see Online Appendix Figure A.1).
} 
cruiter $j$ assigns to candidate $i . N_{i j}$ is a dummy variable for the Four Employers treatment. We also include applicants' score for work attitude $\left(A_{i j}\right)$ and skill and experience $\left(S_{i j}\right)$. We estimate the model using OLS and correct the standard errors to account for interdependence in the error term $\epsilon_{i j}$ at the recruiter level.

Column 1 in Table 5 reports the unconditional effect of the Four Employers treatment: callback likelihood ratings are, on average, 0.66 points lower in the Four Employers than in the One Employer treatment $(p<0.001$, t-test). In Column 2 , we add work attitude and find that the coefficient is close to one and highly significant ( $p<0.001$, t-test). That is, an increase in the perceived level of work attitude by one point increases the callback likelihood rating by roughly one point. Crucially, the Four Employers treatment effect shrinks from -0.663 to -0.282 , which means that our composite measure of work attitude is able to explain $57.5 \%$ of the treatment effect in the survey experiment. ${ }^{39}$

By contrast, although the skill/experience score is positively associated with the callback likelihood, it does not explain much of the treatment effect (see Column 3). While an increase in skill and experience by one point increases the callback likelihood rating by about 0.6 points ( $p=0.002$, t-test), the Four Employers coefficient decreases by only $3 \%$. Hence, perceptions of task-related skills and experience are predictive of the callback likelihood, but they do not help explain why the Four Employers candidates are less likely to be invited for a job interview than the One Employer applicants.

Finally, Column 4 includes both scores simultaneously as regressors. The coefficients of both the Four Employers treatment and work attitude score remain virtually unchanged compared to Column 2. By contrast, the coefficient of skill/experience is close to zero and statistically insignificant ( $p=0.843$, t-test). Hence, perceived work attitude appears to predict callback likelihood ratings more strongly than perceived skill/experience.

\section{Result 6 (Explanatory power of work attitude)}

Recruiters report they are less likely to call back applicants with more frequent job

\footnotetext{
${ }^{39}$ We obtain similar results when applying the Blinder-Oaxaca decomposition method (Blinder 1973; Oaxaca 1973).
} 
changes, and they largely do so because they perceive them to have poorer work attitude relative to those with fewer job changes. Perceptions of task-related skills and experience do not explain the difference in the callback likelihood rating.

\section{Evidence from US Labor Market Panel Data}

In this section, we analyze US labor market panel data to explore the generalizability of our experimental results. Specifically, we use the National Longitudinal Survey of Youth 1997 (NLSY97), a large, nationally representative panel of young Americans, covering a wide range of jobs and industries in the US labor market. This dataset has the advantage of featuring variables that are likely related to work attitude, making it possible to also investigate our first hypothesis. Using these data also allows us to corroborate our results from Switzerland with data from the United States, further testing the external validity of our earlier findings. ${ }^{40}$

\subsection{Number of previous jobs and work attitude}

We begin by testing Hypothesis 1, i.e., whether individual proxies of work attitude correlate with the number of job changes. To this end, we use several measures in the NLSY97 associated with individuals' tendencies to follow rules and comply with desired behavior. For example, we explore whether people who are more likely to break rules, have been arrested by the police and drink at work switch jobs significantly more often than others. We also test whether Big 5 personality traits are associated with the number of job changes.

In our analysis, we regress the total number of jobs since age 20 on measures of work attitude and personality. More precisely, we ran one regression for each of the attitude and personality measures, respectively, including various controls (i.e., the total duration

\footnotetext{
${ }^{40}$ While we would naturally also like to conduct a similar analysis using Swiss panel data, we were unable to obtain a longitudinal panel of Swiss workers with sufficiently long-term and detailed work history, or with additional measures of individual characteristics.
} 
of employment since age 20, the highest educational degree obtained, high school GPA, age, sex, ethnicity, region, urban area and interview month). We adjusted the p-values for multiple hypothesis testing using the Holm-Bonferroni method and normalized each measure to mean zero and standard deviation of one to make the coefficients comparable across regressions. Detailed explanations of the dependent and independent variables in this analysis are in the Online Appendix 4.2.

Figure 6 summarizes the results of this analysis. Individuals who are more likely to break rules, have been arrested by the police and drink at work switch jobs significantly more often $(p<0.01$ from t-tests in each case). Less conscientious labor market participants also switch jobs more often $(p<0.01)$. By contrast, hardworking individuals do not change jobs more frequently relative to others $(p=0.25)$. While emotional stability is unrelated to job switching $(p=0.24)$, being extraverted, agreeable and open to new experiences is associated with a higher frequency of job changes ( $p<0.01$ in each case).

This analysis shows that individual characteristics that seem to be intuitively related to work attitude are often correlated with prior numbers of job changes. This provides further evidence consistent with our first hypothesis.

\subsection{Number of previous jobs and current unemployment status}

We next test Hypothesis 2. We use the NLSY97 data to test whether changing jobs more frequently is associated with an increased likelihood of being unemployed. Figure 7 shows coefficient estimates from regressions of current unemployment status on the number of previous jobs for a variety of different sub-populations and types of jobs. ${ }^{41}$ Each marker in the graph shows the coefficient estimate from one regression.

The first marker shows that, for the full sample, every additional job in a worker's employment history increases the probability of unemployment by 0.47 percentage points $(p<0.01)$. For example, an individual with eight instead of three different jobs since the age of 20 (25th vs. 75th percentile) has more than double the probability of being

\footnotetext{
${ }^{41}$ We include the same additional controls as in the previous analysis.
} 
Figure 6: Number of previous jobs, work attitude, and personality

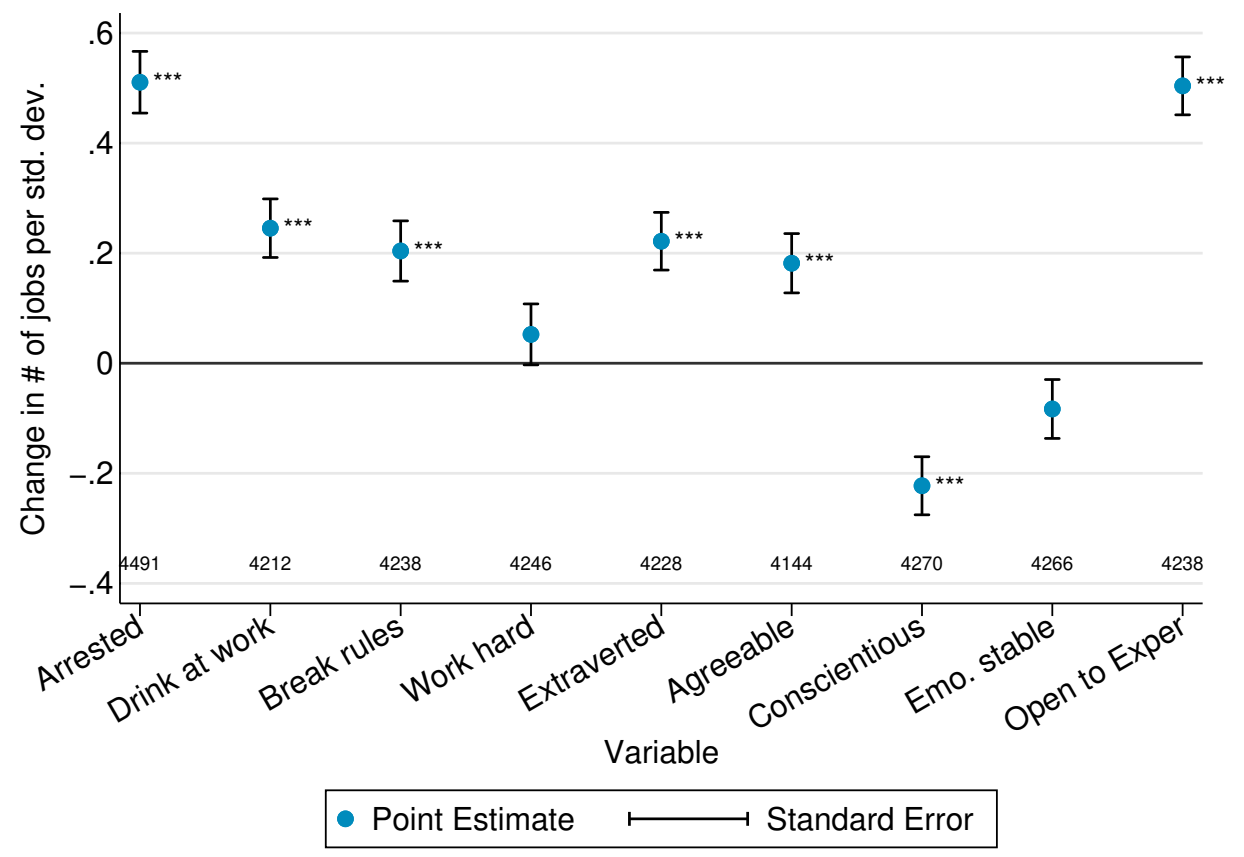

OLS regressions of the number of job changes (Jobs) on measures of work attitude and personality traits controlling for past unemployment, highest academic degree, high-school GPA, age, gender, ethnicity, geographical region, urban/rural area, whether first employment was before or after July 2000, and month in which the interview was conducted. Each dot represents the coefficient of the variable of interest from a separate regression for each of the work attitude and personality measures. All measures of work attitude and personality are normalized to have mean zero and standard deviation of one. The number of observations (at the bottom) varies across regressions because of missing survey responses. The stars next to the dots indicate significance adjusted for multiple hypothesis testing using the Holm-Bonferroni correction. Significance levels: ${ }^{* * *} p<0.01$.

currently unemployed (2.2 vs. $4.6 \%$ ). The remaining markers test the robustness of the above finding across different demographic groups. While in some cases the size of the coefficients varies, they all indicate a positive relationship. This analysis reveals that the positive relationship between prior job changes and unemployment is robust across a variety of demographic groups.

While our primary focus is on employability, we also use the NLSY97 to investigate whether a higher number of previous jobs is negatively related to labor market earnings. Figure A.7 in the Online Appendix repeats the analysis in Figure 7, but with wage 
Figure 7: Relationship between number of previous jobs and current unemployment status

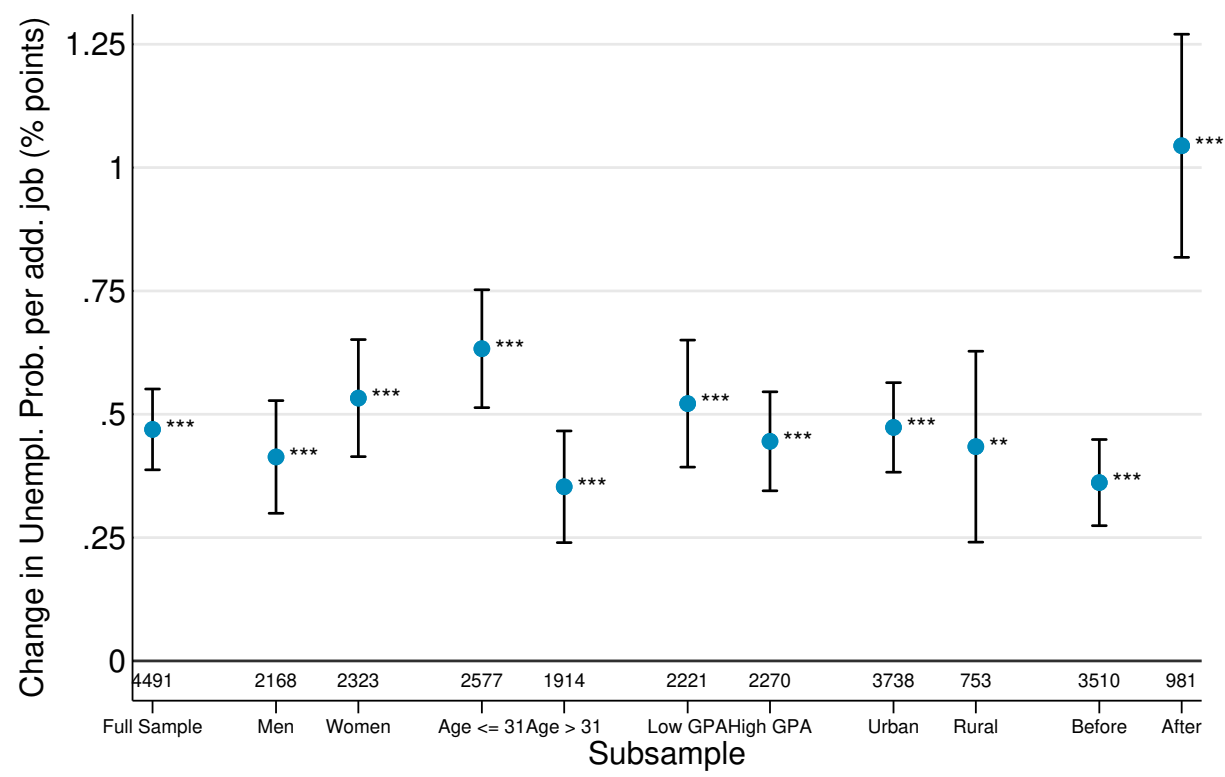

- Point Estimate $\longmapsto$ Standard Error

Coefficients from OLS regressions of current unemployment status (as of the most recent interview wave in 2013/14) on the number of past jobs (since the age of 20) with the same covariates as in Figure 6. Each dot represents a separate regression for the different sub-populations as indicated on the horizontal axis. "Before" and "After" refer to participants who entered the labor market either before or after the third quarter of 2000 (start of the early 2000s downturn). The numbers at the bottom indicate sample size. The stars next to the dots indicate significance with *** $p<0.01$ and $* * p<0.05$.

and salary income in the year before the 2013 wave as the dependent variable. For the full sample, each additional prior job is associated with $\$ 1,504$ lower annual income, on average $(p<0.01) .{ }^{42}$ This relationship is also robust across different subgroups, although the income disadvantage due to frequent job changes is larger for men than for women $(p<0.01)$

\footnotetext{
${ }^{42}$ Our results are consistent with Light and McGarry (1998), who used the earlier NLSY79 panel to show that more frequent job changes are associated with lower earnings.
} 


\section{Conclusion}

This paper puts forth a novel interpretation of the relationship between job changes and employability. We argue that job changes can provide a signal of a worker's work attitude, or cooperativeness, reliability and ability to work well with others. Our motivating hypothesis is that workers who are less cooperative, reliable, team-oriented and generally more difficult to get along with will, holding all else equal, often be the ones who change jobs more frequently. Since the number of times that a worker has changed jobs in the past is a salient aspect of a worker's resume, we expect that prospective employers will use employment history as a signal of work attitude and discriminate against employees who change jobs more frequently.

We combine lab, field and survey experiments, along with analysis of a widely used labor market panel dataset, to test our hypotheses. In the laboratory study, employment history is a reliable signal of work attitude: workers who switch employment less frequently are more likely to fulfill employers' effort requests. Moreover, firms recognize this and exhibit a preference for hiring workers with fewer job changes when this information is available. The laboratory experiment serves as a proof of concept, but leaves open the question of whether similar patterns can be detected in non-laboratory settings.

The rest of our analysis provides evidence that these relationships generalize to real labor markets. In the field experiment we sent out pairs of resumes for open job positionsone resume in which the applicant changed jobs frequently and another in which the applicant remained with a single employer. As in the laboratory, we find that employers exhibit a preference for candidates with fewer job changes: frequent changes result in substantially lower callback rates. To verify that the differential demand for the candidates from the field experiment is due to firms' perceptions of the candidates' work attitude, we conducted a survey experiment with HR professionals. The results confirm that a primary inference recruiters make from the resumes is that workers who switch jobs more frequently have poorer work attitude - particularly regarding reliability, perse- 
verance, and ability to work in teams. Moreover, this perception accounts for a large part of recruiters' stated preferences for the applicant with fewer prior job changes. Finally, we analyze labor market panel data and find evidence consistent with our two hypotheses: workers who exhibit traits negatively related to reliability and work attitude change jobs more frequently and work histories with more prior job changes are related to worse subsequent employment prospects.

Hence, two central results emerge from our studies. First, in all of the contexts we study, firms prefer workers who change jobs less frequently. Second, changing jobs less often is positively correlated and perceived to be correlated with measures of work attitude.

Of course, although we find supportive evidence of these patterns in data from several contexts, we are also aware of potentially important limitations to the external validity of our results. Our analysis focuses on relatively young workers in a narrow set of low- and medium-skilled occupations. Since our study aimed to test whether frequent job changes can signal poor work attitude - rather than testing whether it will always do so - our field experiment and survey study selected occupations and age ranges for which we thought work attitude would likely to be important. Therefore, we believe it is warranted to be critical about the extent to which our results generalize to other populations and jobs with other characteristics. However, our analyses also document that many patterns in our data are robust across different categories of workers and types of jobs. Nevertheless, we fully acknowledge that our findings may not hold in other contexts that we do not explore.

Indeed, while in our studies frequent job changes hurt employability, there are likely contexts in which frequent changes are considered less bad, or may even convey desirable qualities. For example, a higher number of prior job changes may be likely to be more common among older workers and may therefore not be as strong of a negative signal. It is also possible that in certain sectors like academia or the technology industry, frequent job changes are interpreted as a signal of positive traits, such as varied experience, larger professional networks and greater ambition. Any of these aspects may 
mitigate or entirely counteract the effects we observe in our studies. Indeed, we find that industry experience - which is more likely for an applicant with more frequent job changes - increases the likelihood of a favorable response from a prospective employer in our field experiment. Thus, even in our data, there are ways in which employment changes can be beneficial. Furthermore, our analysis focuses primarily on horizontal job changes; in contrast, frequent vertical moves may be much less likely to be perceived negatively when they lead to more challenging and better-paid positions. Hence, we acknowledge that there may be contexts in which the total effect of the frequency of job changes is positive.

Nevertheless, our argument is that where work attitude and reliability are important relative to concerns like those above, the market will often interpret frequent job changes as a negative signal of this quality, so that workers' labor market prospects may be harmed by changing jobs frequently. All of our data is consistent with this relationship. Of course, there may also be other aspects of employment history-including where an individual has worked, what functions they performed and how quickly they were promoted - that can provide evidence of work attitude. Moreover, other aspects of an individual's resume, such as membership in organizations or non-work activities might also provide relevant information. Thus, rather than arguing that job changes, on which we focus, provide the only channel through which work attitude is transmitted, we hope that our paper spurs interest in exploring other related mechanisms through which employers can learn about this valuable employee characteristic.

\section{References}

Ackermann, Kurt A, Jürgen Fleiß, and Ryan O Murphy. 2016. "Reciprocity as an individual difference." Journal of Conflict Resolution 60 (2): 340-367.

Altonji, Joseph G., Anthony A. Smith, and Ivan Vidangos. 2013. "Modeling Earnings Dynamics." Econometrica 81 (4): 1395-1454.

Arrow, Kenneth J. 1973. "Higher education as a filter." Journal of Public Economics 2 (3): 193-216. 
Bagger, Jesper, Fran Fontaine, Fabien Postel-Vinay, Jean-Marc Robin, et al. 2014. "Tenure, Experience, Human Capital, and Wages: A Tractable Equilibrium Search Model of Wage Dynamics." American Economic Review 104 (6): 1551-96.

Bartel, Ann P. 1980. "Earnings Growth on the Job and between Jobs." Economic Inquiry 18 (1): $123-137$.

Bartoš, Vojtěch, Michal Bauer, Julie Chytilová, and Filip Matějka. 2016. "Attention discrimination: Theory and field experiments with monitoring information acquisition." American Economic Review 106 (6): 1437-75.

Becker, Anke, Thomas Deckers, Thomas Dohmen, Armin Falk, and Fabian Kosse. 2012. "The relationship between economic preferences and psychological personality measures." Annual Review of Economics 4 (1): 453-478.

Becker, Brian E., and Stephen M. Hills. 1983. "The Long-Run Effects of Job Changes and Unemployment among Male Teenagers." Journal of Human Resources 18 (2): $197-212$.

Becker, Gary S. 1962. "Investment in Human Capital: A Theoretical Analysis." Journal of Political Economy 70 (5): 9-49.

-1964. Human capital; a theoretical and empirical analysis, with special reference to education. New York: Columbia University Press.

Bedard, Kelly. 2001. "Human capital versus signaling models: university access and high school dropouts." Journal of Political Economy 109 (4): 749-775.

Bellemare, Charles, and Sabine Kröger. 2007. "On representative social capital." European Economic Review 51 (1): 183-202.

Bertrand, Marianne, and Sendhil Mullainathan. 2004. "Are Emily and Greg More Employable Than Lakisha and Jamal? A Field Experiment on Labor Market Discrimination." American Economic Review 94 (4): 991-1013.

Blinder, Alan S. 1973. "Wage discrimination: reduced form and structural estimates." Journal of Human Resources 8 (4): 436-455.

Blumen, Isadore, Marvin Kogan, and Philip J. McCarthy. 1955. The Industrial Mobility of Labor as a Probability Process. Ithaca, NY: Cornell University Press.

Bock, Olaf, Ingmar Baetge, and Andreas Nicklisch. 2014. "hroot: Hamburg registration and organization online tool." European Economic Review 71:117-120.

Borjas, George J. 1981. "Job Mobility and Earnings over the Life Cycle." Industrial and Labor Relations Review 34 (3): 365-376.

Bowles, Samuel, Herbert Gintis, and Melissa Osborne. 2001. "The determinants of earnings: A behavioral approach." Journal of Economic Literature 39 (4): 1137-1176.

Brown, Martin, Armin Falk, and Ernst Fehr. 2004. "Relational contracts and the nature of market interactions." Econometrica 72 (3): 747-780. 
Brüggen, Alexander, and Martin Strobel. 2007. "Real effort versus chosen effort in experiments." Economics Letters 96 (2): 232-236.

Burks, Stephen, Bo Cowgill, Mitchell Hoffman, and Michael Housman. 2015. "The Value of Hiring through Employee Referrals." Quarterly Journal of Economics 130 (2): 805-839.

Carlsson, Magnus, and Dan-Olof Rooth. 2007. "Evidence of Ethnic Discrimination in the Swedish Labor Market Using Experimental Data." Labour Economics 14 (4): 716729.

Cohen, Jacob. 1969. "Statistical power analysis for the biomechanical sciences." L. Erbraum Associates, New York, USA.

Datta, Somnath, and Glen A Satten. 2005. "Rank-sum tests for clustered data." Journal of the American Statistical Association 100 (471): 908-915.

Deming, David J. 2017. "The growing importance of social skills in the labor market." Quarterly Journal of Economics 132 (4): 1593-1640.

Deming, David J, Noam Yuchtman, Amira Abulafi, Claudia Goldin, and Lawrence F Katz. 2016. "The value of postsecondary credentials in the labor market: An experimental study." American Economic Review 106 (3): 778-806.

Dohmen, Thomas, Armin Falk, David Huffman, and Uwe Sunde. 2009. "Homo Reciprocans: Survey Evidence on Behavioural Outcomes." Economic Journal 119 (536): $592-612$.

Dustmann, Christian, and Costas Meghir. 2005. "Wages, Experience and Seniority." Review of Economic Studies 72 (1): 77-108.

Eriksson, Stefan, and Dan-Olof Rooth. 2014. "Do Employers use Unemployment as a Sorting Criterion when Hiring? Evidence from a Field Experiment." American Economic Review 104 (3): 1014-1039.

Farber, Henry S. 1999. "Mobility and Stability: The Dynamics of Job Change in Labor Markets." In Handbook of Labor Economics, edited by Orley. Ashenfelter and David E. Card, vol. 3, Part B, 2439-2483. Elsevier.

Faul, Franz, Edgar Erdfelder, Albert-Georg Lang, and A Buchner. 2007. GPower. 3.0.

Fehr, Ernst, Urs Fischbacher, Bernhard von Rosenbladt, Juürgen Schupp, and Gert G Wagner. 2002. "A Nation-Wide Laboratory." Schmollers Jahrbuch 122:519-542.

Fischbacher, Urs. 2007. "z-Tree: Zurich toolbox for ready-made economic experiments." Experimental Economics 10 (2): 171-178.

Gërxhani, Klarita, Jordi Brandts, and Arthur Schram. 2013. "The emergence of employer information networks in an experimental labor market." Social Networks 35 (4): 541560 .

Ghiselli, Edwin E. 1974. "Some Perspectives for Industrial Psychology." American Psychologist 29 (2): 80-87. 
Gittell, Jody Hoffer. 2005. The Southwest Airlines Way. McGraw Hill Professional.

Granovetter, Mark. 1974. Getting a job: A study of contacts and careers. Cambridge, MA: Harvard University Press.

Green, Francis, Stephen Machin, and David Wilkinson. 1998. "The meaning and determinants of skills shortages." Oxford Bulletin of Economics and Statistics 60 (2): 165187.

Head, Allen, and Huw Lloyd-Ellis. 2012. "Housing Liquidity, Mobility, and the Labour Market." Review of Economic Studies 79 (4): 1559-1589.

Heckman, James J, and Yona Rubinstein. 2001. "The importance of noncognitive skills: Lessons from the GED testing program." American Economic Review 9 (2): 145-149.

Heckman, James J, Jora Stixrud, and Sergio Urzua. 2006. "The Effects of Cognitive and Noncognitive Abilities on Labor Market Outcomes and Social Behavior." Journal of Labor Economics 24 (3): 411-482.

Jovanovic, Boyan. 1979. "Firm-specific capital and turnover." Journal of Political Economy 87 (6): 1246-1260.

Kagel, John, and Peter McGee. 2014. "Personality and cooperation in finitely repeated prisoner's dilemma games." Economics Letters 124 (2): 274-277.

Kroft, Kory, Fabian Lange, and Matthew J Notowidigdo. 2013. "Duration dependence and labor market conditions: Evidence from a field experiment." The Quarterly Journal of Economics 128 (3): 1123-1167.

Lee, Kibeom, and Michael C Ashton. 2004. "Psychometric properties of the HEXACO personality inventory." Multivariate behavioral research 39 (2): 329-358.

Lee, William G. 1994. "A conversation with Herb Kelleher." Organizational Dynamics 23 (2): $64-74$.

Light, Audrey, and Kathleen McGarry. 1998. "Job Change Patterns and the Wages of Young Men." Review of Economics and Statistics 80 (2): 276-286.

Lindqvist, Erik, and Roine Vestman. 2011. "The labor market returns to cognitive and noncognitive ability: Evidence from the Swedish enlistment." American Economic Journal: Applied Economics 3 (1): 101-128.

McCrae, Robert R, and Paul T Costa. 1987. "Validation of the five-factor model of personality across instruments and observers." Journal of personality and social psychology $52(1): 81$.

Mincer, Jacob. 1958. "Investment in Human Capital and Personal Income Distribution." Journal of Political Economy 66 (4): 281-302.

Mincer, Jacob, and Boyan Jovanovic. 1982. "Labor Mobility and Wages." In Studies in Labor Markets, edited by Sherwin Rosen, 21-64. Chicago: University of Chicago Press for NBER. 
Oaxaca, Ronald. 1973. "Male-female wage differentials in urban labor markets." International Economic Review 14 (3): 693-709.

Oberholzer-Gee, Felix. 2008. "Nonemployment Stigma as Rational Herding: A Field Experiment." Journal of Economic Behavior \&S Organization 65 (1): 30-40.

Oreopoulos, Philip. 2011. "Why do Skilled Immigrants Struggle in the Labor Market? A Field Experiment with Thirteen Thousand Résumés." American Economic Journal: Economic Policy 3 (4): 148-171.

Pager, Devah, Bruce Western, and Bart Bonikowski. 2009. "Discrimination in a Low-Wage Labor Market A Field Experiment." American Sociological Review 74 (5): 777-799.

Pallais, Amanda. 2014. "Inefficient Hiring in Entry-Level Labor Markets." American Economic Review 104 (11): 3565-3599.

Petrongolo, Barbara, and Christopher A. Pissarides. 2001. "Looking into the Black Box: A Survey of the Matching Function." Journal of Economic Literature 39 (2): 390431.

Rees, Albert. 1966. "Information networks in labor markets." American Economic Review $56(1 / 2): 559-566$.

Riach, Peter A, and Judith Rich. 2002. "Field Experiments of Discrimination in the Market Place." Economic Journal 112 (483): F480-F518.

Rogerson, Richard, Robert Shimer, and Randall Wright. 2005. "Search-Theoretic Models of the Labor Market: A Survey." Journal of Economic Literature 43 (4): 959-988.

Rustichini, Aldo, Colin G DeYoung, Jon E Anderson, and Stephen V Burks. 2016. "Toward the integration of personality theory and decision theory in explaining economic behavior: An experimental investigation." Journal of Behavioral and Experimental Economics 64:122-137.

SECO, Swiss State Secretariat for Economic Affairs. 2013. "Monthly Labor Market Statistics." https://www.amstat.ch/.

Siegel, Sidney, and N. Castellan John. 1988. Nonparametric Statistics for the Behavioral Sciences. New York: McGraw-Hill.

Spence, Michael. 1973. "Job market signaling." Quarterly Journal of Economics 87 (3): $355-374$.

Stiglitz, Joseph E. 1975. "The theory of "screening," education, and the distribution of income." American Economic Review 65 (3): 283-300.

Suster, Mark. 2010. Never Hire Job Hoppers. They Make Terrible Employees. http: //www . businessinsider . com/mark-suster-never-hire-job-hoppers-neverthey-make-terrible-employees-2010-4. Blog.

Swiss Federal Statistical Office. 2008. Swiss Labour Force Survey. http://www . bfs . admin . ch/bfs/portal/en/index/themen/03/22/publ . html? publicationID= 5625. 
Thielmann, Isabel, and Benjamin E Hilbig. 2015. "The traits one can trust: Dissecting reciprocity and kindness as determinants of trustworthy behavior." Personality and Social Psychology Bulletin 41 (11): 1523-1536.

Topel, Robert H., and Micheal P. Ward. 1992. "Job Mobility and the Careers of Young Men." Quarterly Journal of Economics 107 (2): 439-479.

Trikha, Ritika. 2012. How a Gen-Y Job Seeker can Justify their Job Hopping. http: //money . usnews . com/money/blogs/outside-voices-careers/2012/10/23/howa-geny-job-seeker-can-justify-their-job-hopping. Blog.

Tyler, John H, Richard J Murnane, and John B Willett. 2000. "Estimating the labor market signaling value of the GED." Quarterly Journal of Economics 115 (2): 431468.

Waldman, Michael. 1984. "Job assignments, signalling, and efficiency." RAND Journal of Economics 15 (2): 255-267.

Zhao, Kun, Eamonn Ferguson, and Luke D Smillie. 2016. "Prosocial personality traits differentially predict egalitarianism, generosity, and reciprocity in economic games." Frontiers in psychology 7:1137. 